\title{
Política monetária e taxa de câmbio em uma pequena economia aberta: uma análise empírica para o Brasil
}

Monetary policy and exchange rate in a small open economy: an empirical analysis for Brazil

\section{Abstract}

The objective of this study is to verifyhow monetary policy responds to exchange rate shocks in Brazil underinflation targeting regime, by considering thetwo-way relationship between these variables (monetary policy and exchange rate). Following Bjørnland and Halvorsen (2014), we estimate a structural VAR model that is identified by a combination of sign and short-term (zero) restrictions (Cholesky-sign decomposition). The results obtained show that there is an important and significant response of monetary policy to exchange rate shocks. The response of monetary policy is immediate, which leads us to conclude that neglecting the contemporary interaction between these variables may lead to inaccurate results. Furthermore, there was no significant evidence of any puzzle in response of the exchange rate and inflation to monetary policy shocks.

\section{Keywords}

Structural VAR; monetary policy; exchange rate shocks; Cholesky-sign decomposition; small open economy.

JEL Codes C32; E31; H62.
Andreza Aparecida Palma

Universidade Federal de São Carlos

\section{Resumo}

O objetivo deste artigo é verificar empiricamentea resposta da política monetária (taxa de juros) a choques na taxa de câmbio no Brasil durante o regime de metas de inflação, considerando a relação contemporânea endógena existente entre tais variáveis (política monetária e taxa de câmbio). Seguindo Bjørnland e Halvorsen (2014), será estimado um modelo SVAR (vetor autorregressivo estrutural) identificado através da combinação de restrições de sinais e de curto prazo (decomposição Cholesky-sinal). Os resultados obtidos mostram que há uma resposta importante e significativa da politica monetária a choques na taxa de câmbio. A resposta da política monetária é imediata, o que nos leva a concluir que negligenciar a interação contemporânea entre tais variáveis pode produzir resultados imprecisos. Além disso, não encontramos evidências significativas de qualquer puzzle na resposta da taxa de câmbioe da inflação a choques na política monetária.

\section{Palavras-chave}

VAR Estrutural; politica monetária; choques na taxa de câmbio; decomposição Cholesky-sinal; pequena economia aberta.

Códigos JEL C32; E31; H62. 


\section{Introdução}

Identificar como a política monetária reage a variações na taxa de câmbio é uma questão de bastante relevância teórica e prática para pequenas economias abertas (small open economies), já que nessas economias a taxa de câmbio oferece um canal adicional de transmissão da política monetária, seja pelo efeito direto nos preços de produtos importados, seja pelos efeitos indiretos do câmbio sobre a demanda e oferta agregadas, e sobre as expectativas dos agentes econômicos (Adolfson, 2001).

Em um regime de metas de inflação, a taxa de juros é o principal instrumento de política monetária e não há umconsenso na literatura a respeito do papel da taxa de câmbio (Taylor, 2001). No entanto, aimplementação de uma estratégia de política monetária eficiente necessita da quantificação da reação apropriada da taxa de juros em resposta a variações na taxa de câmbio, bem como do entendimento dos mecanismos de transmissão do câmbio para a política monetária (Bjørland; Halvorsen, 2014). Pequenas economias abertas estão expostas a choques na taxa de câmbio, que podem refletir tanto fatores internos quantos externos (instabilidade política, mudanças repentinas nas expectativas de investidores, etc.).

A questão da influência da taxa de câmbio sobre a política monetária tem recebido bastante atenção da literatura no período recente. No entanto, a maioria dos trabalhos têm focado na estimação de regras de Taylor (função de reação do Banco Central) aumentadas pela taxa de câmbio. ${ }^{1}$ Essa abordagem, em geral, não leva em consideração a simultaneidade existente entre a regra de política monetária e a taxa de câmbio, frequentemente observada no mercado na literatura internacional (ou seja, a taxa de câmbio também reage a choques de política monetária). Nesse caso, seria adequado estimar também uma função de reação para a taxa de câmbio. Lubik e Schorfheide (2007) fazem isso no contexto de um modelo DSGE. Furlani, Laurini e Portugal (2010) fazem algo semelhante para o caso brasileiro e não encontram evidências de que a política monetária responda à taxa de câmbio. Em uma abordagem distinta, Palma e Portugal (2014), estimam as preferências do Banco Central do Brasil e seus resultados indicam que a taxa de câmbio é uma variável relevante na função perda da autoridade monetária.

1 Podemos citar como exemplo, no caso brasileiro, os trabalhos de Oliveira et al. (2013), Minella et al. (2003), Holland (2005), Salgado et al. (2005), Barbosa e Soares (2006), entre outros. 
A maioria dos estudos utilizando VAR para pequenas economias abertas, por exemplo, também ignora essa relação contemporânea entre as variáveis, assumindo uma resposta defasada da política monetária a choques na taxa de câmbio ou uma resposta defasada da taxa de câmbio a choques na política monetária. Como salientam Bjørnland e Halvorsen (2014) e Bjørnland (2008), ambas as abordagens são problemáticas. No primeiro caso, a restrição implica que o Banco Central não utiliza toda a informação corrente disponível na sua tomada de decisão, ou seja, ignora os choques na taxa de câmbio ao escolher a resposta apropriada da taxa de juros. Já a segunda, impõe fortes e implausíveis restrições à flexibilidade da taxa de câmbio. Cabe notar que a literatura empírica tem apontado evidências de que a taxa de câmbio responde instantaneamente a choques, incluindo os choques de política monetária. ${ }^{2}$

Os resultados empíricos de modelos VAR da literatura internacional para pequenas economias abertas apontam para muitos puzzles, principalmente relacionados aos impactos da política monetária sobre a taxa de câmbio. A hipótese de overshooting da taxa de câmbio (Dornbush, 1976), por exemplo, determina que em resposta a um choque de política monetária contracionista (aumento da taxa de juros), a taxa de câmbio deveria apreciar imediatamente e, após, depreciar-se (de acordo com a hipótese da paridade descoberta da taxa de juros ${ }^{3}$ ). No entanto, os estudos empíricos frequentemente encontram o que se denominou de delayed overshooting ${ }^{4}$ ou forward discount puzzle, ou seja, uma apreciação da taxa de câmbio que ocorre por um período prolongado de tempo, após uma depreciação inicial. Há evidências empíricas, ainda, de uma resposta contrária à prevista pela hipótese de overshooting de Dornbusch, ou seja, o câmbio deprecia em resposta a um aumento da taxa de juros (política monetária contracionista), o que se denomina na literatura de exchange rate puzzle. Em relação ao nível de preços, algumas evidências empíricas também revelam resultados contraintuitivos, como o price puzzle, ou seja, um aumento da inflação após um choque de política monetária contracionista (Eichenbaum, 1992). ${ }^{5}$

2 Veja, por exemplo, Bonser-Neal et al. (1998), Kearns e Manners (2006).

3 A formulação mais simples da paridade descoberta da taxa de juros postula que a mudança esperada na taxa de câmbio é igual ao diferencial entre as taxas de juros nominais interna e externa.

4 As primeiras evidências foram fornecidas por Eichenbaume Evans (1995).

5 De acordo com Bjørnland (2008), esses puzzles têm sido tratados na literatura como fatos estilizados. 
Vários estudos têm tentado levar em consideração esses puzzles. Particularmente, uma série de propostas que são relacionadas à identificação de modelos SVAR. De acordo com Bjørnland (2009), o maior desafio quando se aplica modelos SVAR para economias abertas é como tratar adequadamente a questão da simultaneidade entre política monetária e taxa de câmbio. Ao não permitir essa relação contemporânea entre as variáveis, os resultados obtidos podem ser viesados. Faust e Rogers (2003), por exemplo, mostram que os efeitos da política monetária na taxa de câmbio são sensíveis às restrições de curto prazo impostas na relação contemporânea entre estas variáveis. Kim e Roubini (2000) e Zettelmeyer (2004) também enfatizaram essa questão.

Recentemente, restrições de sinais têm sido bastante usadas na literatura para alcançar a identificação dos modelos VAR, com o atrativo de evitar o uso de restrições fortes na relação contemporânea entre as variáveis. No entanto, Fry e Pagan (2011), mostram que restrições de sinais implicam em uma forma fraca de identificação, uma vez que ela não é única e, portanto, existem muitas funções de resposta ao impulso que podem satisfazer as restrições. Faust e Rogers (2003) também não encontram resultados robustos usando a identificação de sinais. Dessa forma, Bjørnland (2009) afirma que é necessário que a identificação sejaúnica, mantendo a interação entre política monetária e taxa de câmbio asseguradas. Fazendo isso através da utilização de restrições de longo prazo, ${ }^{6}$ por exemplo, a autora encontra evidências (usando o período de 1983 a 2004) de que a hipótese de overshooting de Dornbush é válida para quatro economias abertas: Canadá, Nova Zelândia, Suécia e Austrália.

Bjørnland e Halvorsen (2014), estudando seis pequenas economias abertas (Canadá, Nova Zelândia, Austrália, Suécia, Nourega e Reino Unido), não encontram evidências de qualquer puzzle ao levar em consideração a relação contemporânea entre a taxa de câmbio e a política monetária. Seus resultados apontam para um efeito de choques de política monetária na taxa de câmbio consistente com a hipótese de overshooting de Dornbush. Além disso, encontram um efeito expressivo da taxa de juros em resposta a um choque positivo na taxa de câmbio (depreciação da taxa de câmbio) para todos os países analisados.

Dado o exposto acima, o objetivo deste trabalho é analisar as interações entre a taxa de câmbio e a política monetária no Brasil durante o regime de 6 O trabalho assume que choques de política monetária não têm efeito de longo prazo no nível da taxa de câmbio, enquanto permite que esse efeito seja livre no curto prazo. 
metas de inflação, buscando responder à questão de como a política monetária tem reagido a choques na taxa de câmbio. Dada a discussão anterior, levaremos em consideração a relação simultânea entre a taxa de câmbio e a política monetária, utilizando a metodologia proposta pelo trabalho de Bjørnland e Halvorsen (2014). Será estimado um modelo SVAR identificado por uma combinação de restrições de sinal e de curto prazo (decomposição Cholesky-sinal) que preserva a relação contemporânea endógena entre a taxa de câmbio e a política monetária. A restrição de sinal utilizada é que dado um choque de política monetária contracionista (aumento da taxa de juros), a taxa de câmbio diminui imediatamente (ou seja, aprecia), fato consistente com modelos macroeconômicos estabelecidos. ${ }^{7}$ É importante ressaltar que essa restrição é válida apenas no primeiro período. Nos períodos subsequentes, a taxa de câmbio é livre para se movimentar em qualquer direção, ou seja, não há restrições para a resposta máxima, que pode ser imediata ou defasada (dessa forma, não estamos excluindo a possibilidade de haver delayed overshooting). Restringindo a resposta da taxa de câmbio apenas, é possível verificar como a política monetária responde a choques nesta variável. As restrições de curto prazo seguem o padrão na literatura para economias fechadas, ${ }^{8}$ ou seja, é identificada uma estrutura recursiva entre as variáveis domésticas e a política monetária, de forma que a política monetária reage a todos os choques, porém as variáveis macroeconômicas (produto, inflação, etc.) reagem com uma defasagem aos choques de política monetária. Dessa forma, busca-se fornecer evidências mais robustas a fim de entender a interação entre política monetária (via taxa de juros) e taxa de câmbio em um contexto de uma pequena economia aberta.

O restante deste artigo está organizado da seguinte forma. A seção 2 apresenta a metodologia utilizada, descrevendo o VAR estrutural para uma pequena economia aberta e as restrições utilizadas para sua identificação. A seção 3 apresenta os dados e os resultados empíricos para o Brasil, considerando o regime de metas de inflação. Na seção 4, é feita uma comparação

7 A evidência empírica brasileira quanto à existência de exchange rate puzzle é inconclusiva (ainda temos uma história recente de adoção do regime de câmbio flutuante e relativamente poucos trabalhos que tratam dessa questão). Ivrendi e Yildirim (2013) encontram evidências de uma apreciação da taxa de câmbio em resposta a um choque de política monetária contracionista para o Brasil e outras economias emergentes. Carvalho e Vali (2011), utilizando um modelo DSGE, encontram resultado semelhante, ou seja, dado um aumento na taxa de juros, a taxa de câmbio aprecia. Já Kohlscheen (2013) encontra resultado oposto, ou seja, a taxa de câmbio deprecia em resposta a um choque de política monetária contracionista.

8 Christiano, Eichenbaume Evans (1999). 
dos resultados com outros procedimentos de identificação (decomposição recursiva de Cholesky e Cholesky-sinal robusta). A seção 5 apresenta análise de robustez dos resultados. A última seção é dedicada às conclusões.

\section{SVAR para uma pequena economia aberta e a iden- tificação Cholesky-sinal}

Este trabalho usará a metodologia proposta por Bjørnland e Halvorsen (2014), ou seja, a identificação do modelo VAR estrutural por meio da restrição Cholesky-sinal. Como discutido anteriormente, esse procedimento de identificação busca conservar a relação endógena entre a taxa de câmbio e a política monetária, questão discutida na seção anterior.

Serão incluídas cinco variáveis no modelo, ${ }^{9}$ descritas pelo vetor $X_{t}$ (taxa de inflação, produto real, taxa nominal de juros de curto prazo doméstica, taxa nominal de juros de curto prazo externa e taxa de câmbio). Um $\operatorname{VAR}(p)$ - vetor autorregressivo de ordem $p$ - na forma reduzida será estimado de acordo com a equação (1):

$$
B(L) X_{t}=e_{t}, \operatorname{com} \sum_{e}=E\left(e_{t} e_{t}^{\prime}\right)
$$

em que $\mathrm{L}$ é o operador defasagem, $\mathrm{B}(\mathrm{L})$ é uma matriz polinomial de or$\operatorname{dem} 5 \operatorname{com~} \mathrm{B}(\mathrm{L})=\sum_{i=0}^{p} A_{i} L^{i}$, e $\mathrm{A}_{0}=\mathrm{I}_{5}$. $\mathrm{O}$ termo $e_{t}$ é o erro de previsão um passo à frente, normalmente distribuído com matriz de covariância positiva semidefinida dada por $\Sigma_{e}$. Desde que $\mathrm{B}(\mathrm{L})$ seja invertível, o modelo $\operatorname{VAR}(\mathrm{p})$ pode ser escrito na representação em médias móveis (MA), dada por:

$$
X_{t}=C(L) e_{t}
$$

onde $\mathrm{C}(\mathrm{L})=\mathrm{B}(\mathrm{L})^{-1}$.

O termo de erro $e_{t}$ é linearmente relacionado ao vetor de choques estruturais ortogonais $\epsilon_{t}=\left[\begin{array}{lllll}\epsilon_{t}^{i} & \epsilon_{t}^{y} & \epsilon_{t}^{\pi} & \epsilon_{t}^{P M} & \epsilon_{t}^{C}\end{array}\right]$, normalizado para ter variância unitária $\left(e_{t}=A \epsilon_{t}\right)$. Substituindo na equação (2), temos a reprepequenas economias abertas (ver, por exemplo, Svensson (2000); Clarida, Galí e Gertler (2001)). 
sentação em médias móveis, em termos de choques estruturais:

$$
X_{t}=D(L) \epsilon_{t}
$$

$\operatorname{com} \mathrm{D}(\mathrm{L})=\mathrm{C}(\mathrm{L}) \mathrm{A}$ e $\epsilon_{t} \sim N\left(0, \operatorname{diag}\left(I_{5}\right)\right.$

O foco do presente trabalho é identificar os choques de política monetária $\left(\epsilon_{t}^{P M}\right)$ e taxa de câmbio $\left(\epsilon_{t}^{C}\right)$. Para tanto, realizaremos a partição da matriz A em dois blocos: $\mathrm{A}=$ [A'A"]. A matriz $\mathrm{A}^{\prime}=\tilde{A} Q^{\prime}$ contém o impacto imediato dos choques estruturais que não serão identificados (matriz de ordem $5 \times 3)$. A matriz $\mathrm{A}^{\prime \prime}=\tilde{A} Q^{\prime \prime}=\left[a^{P M}, a^{E S}\right]$ contém o impacto imediato dos choques estruturais que serão identificados, ou seja, choques de política monetária e taxa de câmbio (matriz de ordem $5 \times 2$ ).

Para determinarmos como a política monetária responde a movimentos na taxa de câmbio, será imposta a restrição de que a taxa de câmbio se aprecia (ou seja, diminui) em resposta a um choque de política monetária contracionista (aumento na taxa de juros). Note que essa restrição é consistente com a literatura empírica internacional, baseada em estudos de evento e em Bjørnland (2009), que usa restrições de neutralidade de longo prazo para identificar o modelo VAR. ${ }^{10}$ Essa restrição de sinal é válida para um período apenas, o que permite que a taxa de câmbio se movimente em qualquer direção nos períodos subsequentes (ou seja, é possível que seja verificado o efeito de delayed overshooting). Note que a única restrição imposta neste estágio é sobre a resposta da taxa de câmbio. Dessa forma, será possível verificar os efeitos de variações na taxa de câmbio sobre a política monetária, que é o foco principal do presente trabalho.

Além da restrição de sinal descrita acima, será imposta a restrição de que choques de política monetária têm um impacto defasado (ou seja, não imediato) na inflação, produto e taxa de juros externa. ${ }^{11}$ Já um choque na taxa de câmbio também afetará o produto e a inflação com uma defasagem, devido à existência de pass-through incompleto. A política monetária pode reagir a todos os choques. Então, a identificação será feita da forma

10 Veja, por exemplo, Bonser-Neal et al. (1998), Kearns e Manners (2006), Faust e Rogers (2003), Bjørnland (2009).

11 Já que dada a existência de rigidez nominal existe um processo lento de repassse (pass-through) dos efeitos de política monetária sobre as variáveis macroeconômicas (Christiano, Eichenbaum e Evans (1999)). Além disso, deve-se notar que em uma pequena economia aberta, a política monetária interna não deve afetar as taxas de juros internacionais. 
recursiva padrão, de forma já bem estabelecida na literatura para economias fechadas e, portanto, menos controversa. ${ }^{12}$

As restrições descritas acima são representadas pela matriz $A^{\prime \prime}$ dada abaixo:

$$
A^{\prime \prime}:\left[\begin{array}{cc}
0 & 0 \\
0 & 0 \\
0 & 0 \\
1 & \text { livre } \\
- & 1
\end{array}\right]\left[\begin{array}{c}
\pi_{t} \\
y_{t} \\
i_{t}^{*} \\
i_{t} \\
\theta_{t}
\end{array}\right]
$$

A estimação do modelo descrito nesta seção será feita com o uso de métodos bayesianos, descritos em Bjørnland e Halvorsen (2014) ${ }^{13}$ As prioris dos coeficientes (forma reduzida) e da matriz de covariância são escolhidas de forma a serem não informativas. Especificamente, utilizaremos a distribuição uniforme $(\mathrm{U}(0,2 \pi))$. Tendo como base o procedimento de identificação proposto, os três primeiros choques do modelo VAR serão identificados com a decomposição de Cholesky, com base em simulações do VAR estimado. Para os dois últimos choques, a restrição de sinais será implementada. Para cada draw do VAR a posteriori estimado, será calculada a função de resposta ao impulso e verificado se a restrição de sinal é satisfeita. Se for, a simulação será mantida, caso contrário, descartada. Os intervalos de confiança serão calculados com base em todas as simulações aceitas.

\section{Resultados empíricos usando a decomposição Cho- lesky-sinal}

Para a estimação do modelo SVAR, utilizaremos os dados trimestrais para o período pós-metas de inflação (2000 T1 a 2015 T1) no Brasil, descritos abaixo. Todas as variáveis, com exceção dos preços, são utilizadas em nível, seguindo Bjørnland e Halvorsen (2014). ${ }^{14}$ Além disso, usaremos uma tendência linear para a equação do produto, em vez de usar o hiato do pro-

12 Veja, por exemplo, Christiano, Eichenbaume Evans (1999).

13 O procedimento é muito similar ao descrito por Uhlig (2005).

14 Dessa forma, qualquer relação de cointegração será implicitamente determinada pelo modelo, evitando, ademais, o problema de inconsistência dos parâmetros ao se impor restrições de cointegração incorretas. A esse respeito, consultar também Sims e Uhlig (1991). Essa estratégia foi utilizada também por Lima, Maka e Alves (2011). 
duto, como tentativa de modelar implicitamente a tendência no modelo. ${ }^{15}$

$\pi_{t}$ : taxa de inflação (variação anual), medida pelo IPCA. Fonte: IBGE.

$y_{t}$ : logaritmo do PIB (a preços de mercado) trimestral. Fonte: IBGE.

$\theta_{t}:$ logaritmo dataxa de câmbio nominal R \$/US\$ (compra - média) Fonte: Banco Central do Brasil.

$i_{t}$ : Taxa SELIC Overnight trimestral ${ }^{16}$

Fonte: Banco Central do Brasil.

$i_{t}^{*}$ : Taxa de juros do FED - \% a.a. (Federal Funds rate). Fonte: FMI/IFS.17

O modelo foi estimado usando as variáveis acima descritas, com quatro defasagens. Versões do modelo com diferentes números de defasagens também foram estimadas, sem alteração significativa nos principais resultados. As funções de resposta ao impulso, obtidas via decomposição de Cholesky-sinal, são apresentadas na figura 1. As linhas em preto representam a resposta mediana e as linhas pontilhadas são os percentis de ordem 16 e 84, respectivamente. A coluna da esquerda mostra a resposta das variáveis a um choque na taxa de juros e a coluna da direita a resposta das variáveis a um choque na taxa de câmbio. É importante notar que as respostas da taxa de juros e da taxa de câmbio são contemporâneas, enquanto as respostas das demais variáveis são defasadas. Para facilitar a interpretação, os choques foram normalizados de forma a aumentar a taxa de juros em um ponto percentual (choque de política monetária contracionista) e aumentar (depreciar) a taxa de câmbio em 1\%. A seguir, analisaremos primeiramente os efeitos dos choques de política monetária sobre as variáveis e, posteriormente, os efeitos dos choques na taxa de câmbio sobre a política monetária, que é o foco do presente trabalho. ${ }^{18}$

15 A esse respeito, consultar Lindé (2003). Essa estratégia foi utilizada também por Bjørnland e Halvorsen (2014). Foi estimado, também, um modelo com o hiato do produto e os principais resultados não sofreram alterações significativas.

16 As taxas mensais foram acumuladas de forma a se obter a taxa trimestral.

17 Refere-se à fonte original. Os dados foram coletados no site do IPEADATA.

18 Os correlogramas dos resíduos do modelo estimado na forma reduzida são apresentados no apêndice B. Como pode ser observado, os resíduos em geral não apresentam autocorrelações e correlações cruzadas, o que indica que o modelo estimado é adequado. 
Figura 1 Resposta a choques de política monetária e taxa de câmbio

Decomposição Cholesky-Sinal

\section{Impulso Resposta}

\section{Choque PM}
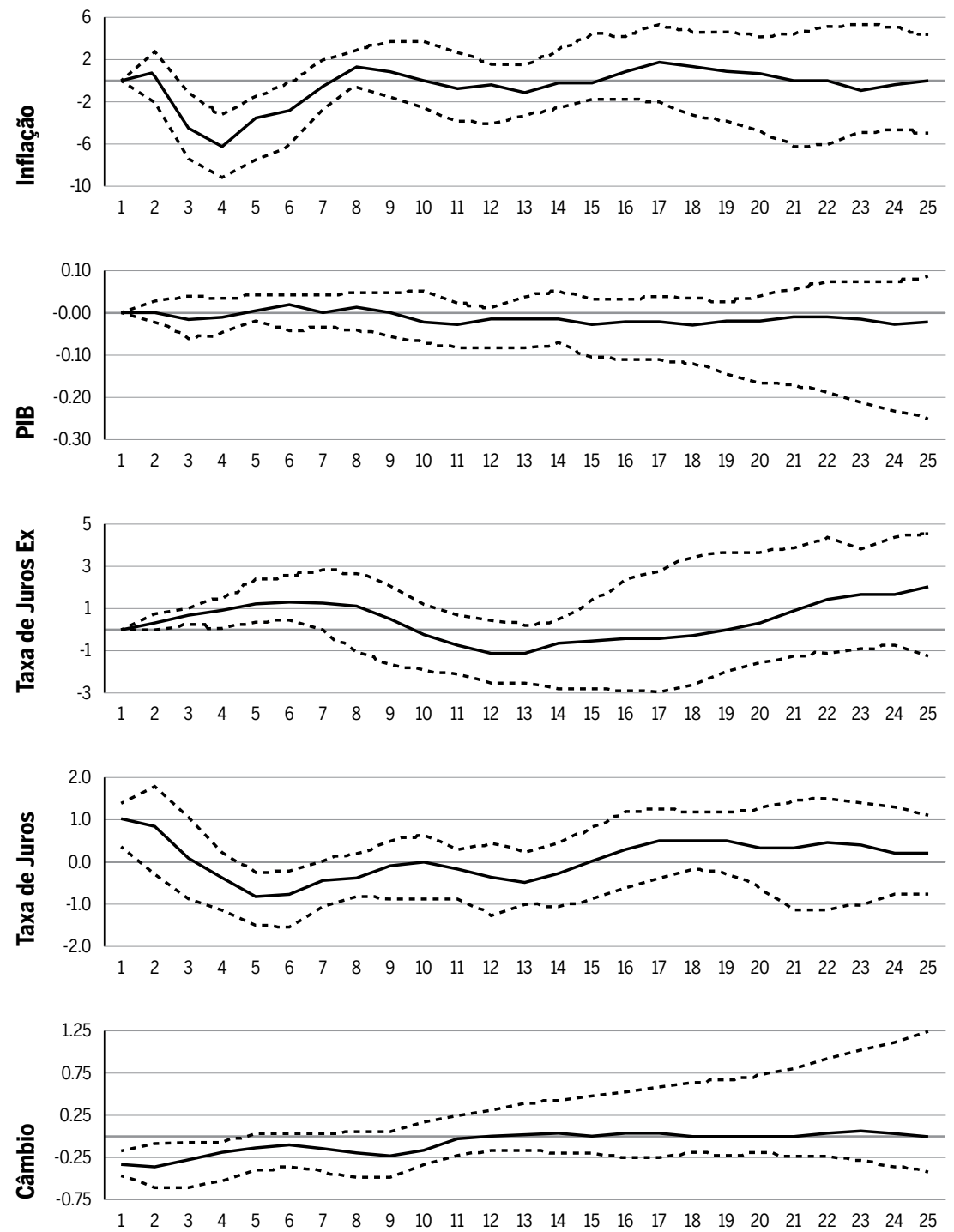


\section{Impulso Resposta}

\section{Choque Câmbio}
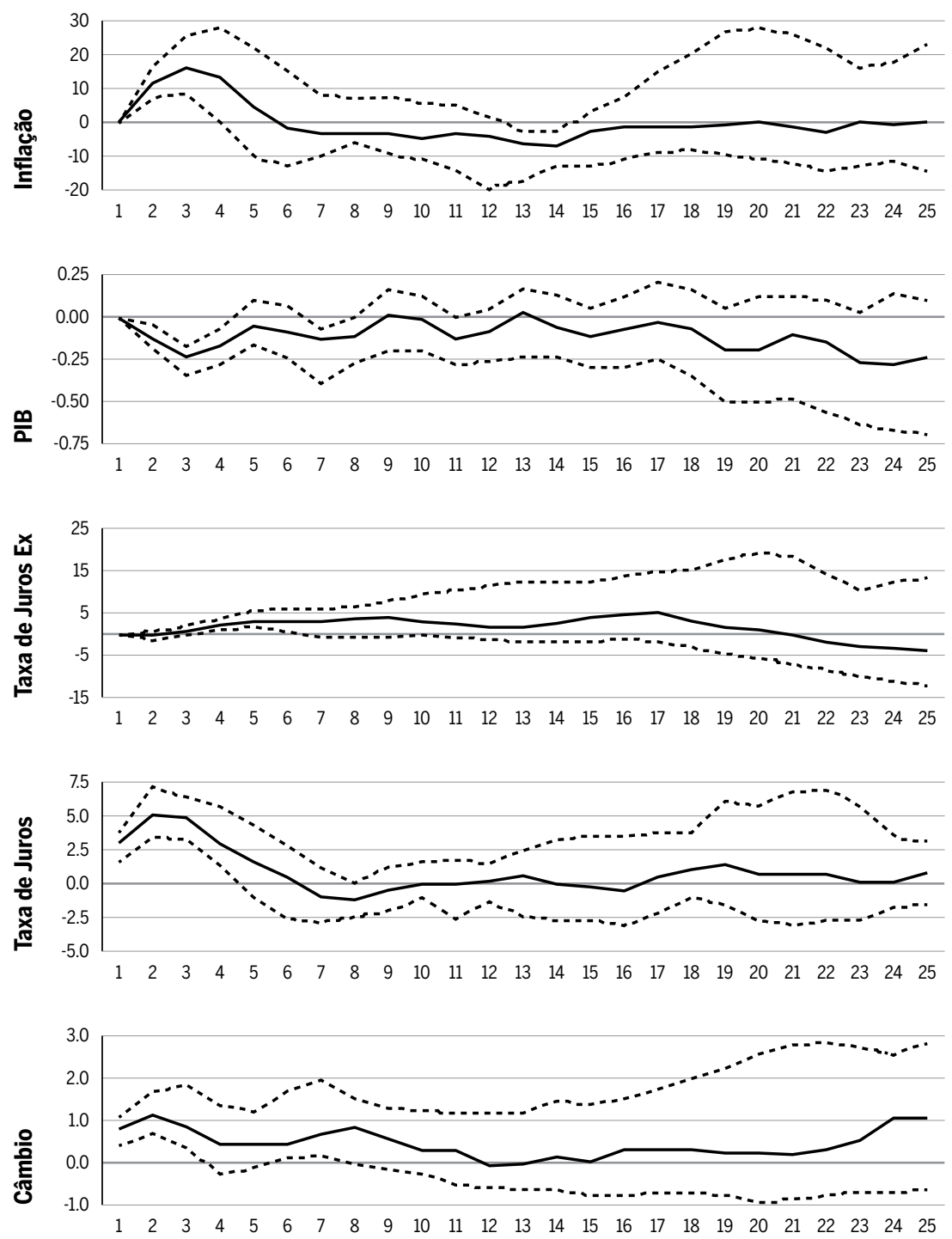

Fonte: Saída do software RATS. 


\subsection{Os efeitos dos choques de política monetária}

Os choques de política monetária têm, em geral, os efeitos usuais encontrados na literatura. Em resposta a um choque de política monetária contracionista (ou seja, aumento da taxa de juros), podemos observar que taxa de câmbio se aprecia imediatamente (conforme foi assumido para alcançarmos a identificação). Após o efeito inicial, a taxa de câmbio tende a voltar gradualmente ao seu valor original (entre 2 e 3 trimestres o efeito se torna não significante), fato consistente com a hipótese de overshooting de Dornbusch. Existe algum grau de inércia da taxa de juros no modelo (gradual redução da taxa de juros dado um choque de política monetária) ${ }^{19}$ em reposta a um choque de política monetária. Quanto ao efeito sobre a inflação, há um pequeno aumento inicial (embora não significativo estatisticamente), seguido de queda ${ }^{20}$, alcançando o máximo efeito de queda em 3-4 trimestres, fato consistente com algum grau de rigidez de preços. Os resultados não apontam para evidências significativas de price puzzle, ou seja, de uma resposta positiva significante estatisticamente da inflação frente a um choque contracionista de política monetária. Os resultados obtidos são consistentes com os reportados em Lima, Maka e Alves (2011), que encontraram uma resposta defasada do nível de preços frente a um choque de política monetária. Evidências de price puzzle foram encontradas especialmente para o Reino Unido no estudo tomado como base. Já os efeitos sobre o produto não são estatisticamente diferentes de zero. Efeito semelhante para o produtofoi encontrado paraos casos do Canadá, Nova Zelândia, Suécia e Reino Unido por Bjørland e Halvorsen (2014). Apenas para os casos da Austrália e Noruega encontrou-se uma resposta significativa e negativa para o produto frente a um choque contracionista de política monetária.

\subsection{Choques na taxa de câmbio e Política Monetária}

O foco do presente trabalho é verificar como a política monetária reage a um choque na taxa de câmbio. Isso pode ser analisado através da coluna

19 A inércia na taxa de juros permite ao Banco Central suavizar os efeitos da política ao longo do tempo, afetando as expectativas do setor privado.

20 Alguns estudos têm encontrado uma reação inicial positiva e significativa da inflação em resposta a choques de política monetária, denominado de price puzzle. 
direita na figura 1. É importante notar que os resultados foram obtidos sem impor qualquer restrição na reposta da taxa de juros doméstica ao choque cambial. Dado um choque na taxa de câmbio (depreciação, ou seja, aumento na taxa de câmbio), a taxa de juros responde com um aumento inicial significativo. $O$ aumento inicial gradualmente se dissipa, tornando-se insignificante ao longo do tempo (aproximadamente em 4-5 trimestres). Portanto, o Banco Central responde instantaneamente e persistentemente a um choque na taxa de câmbio. E essa resposta se dá no intervalo de um ano. Esse resultado não nos permite afirmar explicitamente que a autoridade monetária leva em consideração na sua função aperda da taxa de câmbio, já que podem existir efeitos indiretos consideráveisda taxa de câmbio sobre os juros. É importante notar que não considerar os efeitos contemporâneos entre a política monetária e a taxa de câmbio pode levar a resultados imprecisos, já que como podemos observar pelos resultados obtidos, a resposta da política monetária a choques na taxa de câmbio é imediata. Estudos que assumem resposta defasada dos choques cambiais na política monetária podem subestimar o papel da taxa de câmbio no mecanismo de transmissão da política monetária. Bjørland e Halvorsen (2014) encontraram resultados semelhantes para quatro dos países analisados: Canadá, Nova Zelândia, Noruega e Suécia. Nesses países, a resposta da taxa de juros a um choque na taxa de câmbio foi positiva e significativa. Para Austrália e Reino Unido, o efeito encontrado não foi estatisticamente diferente de zero, indicando que nesses países a taxa de juros não responde a choques na taxa de câmbio.

A tabela 1 apresenta os resultados da decomposição da variância para a taxa de juros. De acordo com esses resultados, podemos concluir que a taxa de câmbio possui um papel importante para explicar movimentos na taxa de juros, explicando aproximadamente $36 \%$ da sua variação inicial, efeito que aumenta ao longo do horizonte de previsão. Bjørnland e Halvorsen (2014) encontram evidências de que a taxa de câmbio é importante para explicar a variância da taxa de juros nos casos do Canadá, Nova Zelândia, Noruega e Suécia. Já para o Reino Unido e Austrália, esse efeito é insignificante. Cabe notar que os valores encontrados para o Brasil são bem mais expressivos do que os apresentados em Bjørnland e Halvorsen (2014) para qualquer um dos países, indicando que no caso brasileiro a resposta da taxa de juros a choques na taxa de câmbio é mais forte e com efeitos mais duradouros do que nos países analisados pelo estudo tomado como base. 
Tabela 1 Decomposição da variância (taxa de juros)

\begin{tabular}{lrrrr}
\hline Horizonte/Choques & Política Monetária & Taxa de Câmbio & Outros \\
\hline 1 passo a frente & 0.322628 & 0.366836 & 0.310535 \\
\hline 4 passos a frente & 0.114269 & 0.576404 & 0.309327 \\
\hline 8 passos a frente & 0.167190 & 0.534374 & 0.298436 \\
\hline
\end{tabular}

Fonte: Saída do software RATS.

\section{Decomposição de Cholesky, Cholesky-sinal e Cho- lesky-sinal robusta: comparação dos resultados}

Nesta seção, é realizada a comparação dos resultados obtidos com dois outros procedimentos de identificação do modelo SVAR. É considerada a decomposição recursiva de Cholesky, com a taxa de juros ordenada antes da taxa de câmbio. Além disso, assim como em Bjørnland e Halvorsen (2014), também realizamos a identificação do modelo levando em consideração a questão da incerteza, como reportado por Fry e Pagan (2011). ${ }^{21}$ Os resultados são apresentados na figura 2, para as duas principais variáveis de interesse, a taxa de juros e a taxa de câmbio. ${ }^{22}$

O efeito de um choque de política monetária sobre a taxa de câmbio é bastante distinto. Com a decomposição de Cholesky, um choque de política monetária levaria a uma depreciação (aumento) da taxa de câmbio. Usando a decomposição Cholesky-sinal, assumimos que taxa de câmbio se aprecia imediamente após um choque de política monetária no período inicial, efeito que se mantém nos períodos subsequentes. Quanto ao efeito do choque na taxa de câmbio sobre a taxa de juros, pode-se notar que o efeito é bem menos expressivo quando consideramos a identificação via decomposição recursiva de Cholesky. De fato, Bjørnland e Halvorsen (2014) concluem que a reação das variáveis frente a choques na taxa de câmbio e política monetária será subestimada se não for considerada adequadamente a interação entre essas variáveis. Ademais, apresentamos na tabela 2 os resultados comparativos da análise de decomposição da variância, que estão em consonância com os resultados acima.

21 Ou seja, o fato de que os resultados da identificação via restrição de sinais podem ser gerados por duas matrizes diferentes que não são necessariamente ortogonais entre si.

22 Assim como na seção anterior, os choques foram normalizados (aumento de 1 ponto percentual na taxa de juros e $1 \%$ na taxa de câmbio). 
Figura 2 Resposta a choques de política monetária e taxa de câmbio:

Cholesky-sinal, Cholesky e Cholesky-sinal robusta ${ }^{23}$

\section{Impulso Resposta}

Choque PM
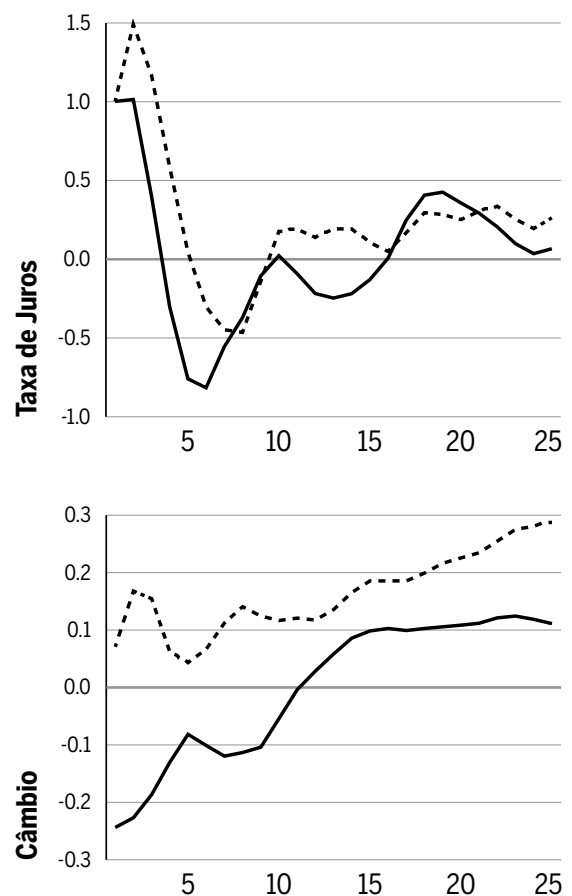

Choque Câmbio
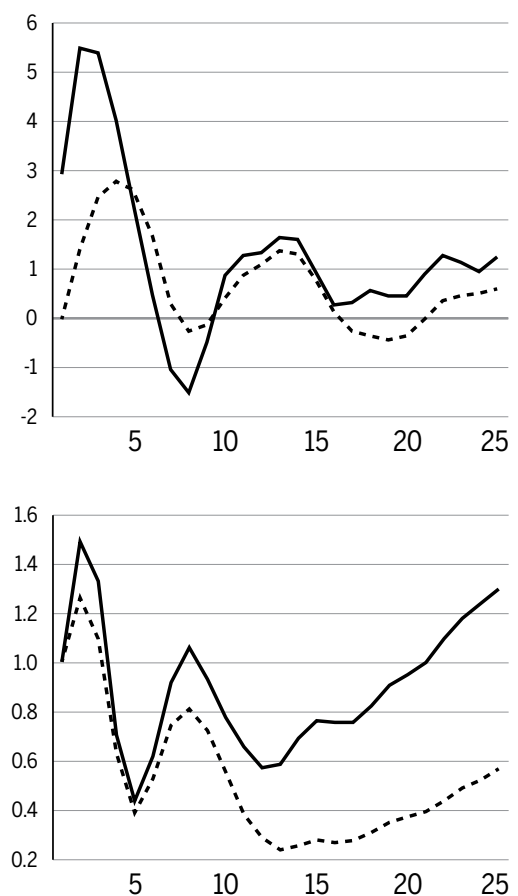

Fonte: Saída do software RATS.

Nota: Decomposição Cholesky-sinal (linha sólida), decomposição de Cholesky (linha pontilhada) e decomposição Cholesky-sinal robusta (linha tracejada).

Tabela 2 Decomposição da variância - choques na taxa de câmbio sob a taxa de juros

\begin{tabular}{l|r|r|r}
\hline $\begin{array}{l}\text { Horizonte/ } \\
\text { Identificação }\end{array}$ & Cholesky-sinal & $\begin{array}{r}\text { Cholesky-sinal } \\
\text { robusta }\end{array}$ & Cholesky \\
\hline 1 trimestre & 0.366836 & 0.366836 & 0.000000 \\
\hline 4 trimestres & 0.576404 & 0.576404 & 0.153803 \\
\hline 8 trimestres & 0.534374 & 0.534374 & 0.202663 \\
\hline
\end{tabular}

Fonte: Saída do software RATS.

23 Note que para esse caso, a identificação via Cholesky-sinal e Cholesky-sinal robusta são praticamente idênticas e, portanto, não distinguíveis na figura. 


\section{Análise de Robustez}

Para verificar a robustez dos resultados encontrados, realizamos as alterações descritas a seguir no modelo estimado.

a) Variáveis utilizadas. Foram estimados modelos com o hiato do produto $^{24}$ (excluindo a tendência), com a taxa de câmbio real efetiva ${ }^{25}$ e com a variação da taxa de câmbio.

b) Número de defasagens utilizadas. O modelo foi estimado considerando duas defasagens.

c) Variáveis adicionais. Foi incluída como variável exógena o índice de preços de commodities, calculado pelo Banco Central do Brasil (IC-Br).

d) Quebras estruturais. Foram estimados modelos com algumas variáveis dummies a fim de captar possíveis quebras estruturais na economia brasileira no período considerado. Especificamente, incluímos uma variável dummy para o efeito Lula (2002:4 e 2003:1), outra paraa crise de 2008 (2008:4 e 2009:1) e, finalmente, uma variável dummy para o efeito Tombini (a partir de 2011:1).

Como pode ser verificado pelas figuras A.1-A.8 (inseridas no apêndice A), em geral, os principais resultados não se alteram. Em algumas versões do modelo, é verificada uma resposta positiva do produto dado um choque de política monetária contracionista. No entanto, essa resposta não é estatisticamente significativa. Em especial, a interação entre as respostas da taxa de câmbio e da política monetária se mantém.

\section{Conclusões}

O presente trabalho buscou verificar os efeitos de choques na taxa de câmbio sobre a política monetária, considerando a existência de interação entre essas variáveis. Há evidência empírica na literatura internacional, usando dados intradiários, que a taxa de câmbio reage imediatamente a choques, incluindo os choques de política monetária. Se a política mone-

24 Calculado a partir do filtro de Hodrick-Prescott.

25 Foi utilizado o logaritmo da taxa de câmbio efetiva real. Fonte: BIS - Bank for International Settlements. 
tária também reage rapidamente a surpresas na taxa de câmbio, espera-se que a interdependência contemporânea entre essas variáveis seja importante na análise da política monetária de pequenas economias abertas e negligenciá-la pode levar a resultados viesados. De fato, Bjørnland e Halvorsen (2014) mostraram que essa interação é importante, analisando seis pequenas economias abertas (Austrália, Nova Zelândia, Canadá, Noruega, Reino Unido, Suécia).

Neste trabalho, estimamos um modelo SVAR utilizando uma combinação de restrições de sinais e de curto prazo (decomposição Cholesky-sinal), conforme a metodologia proposta por Bjørnland e Halvorsen (2014), que preserva a relação contemporânea entre a taxa de câmbio e a política monetária. A restrição de sinal utilizada é que a taxa de câmbio se aprecia em resposta a um choque de política monetária (válida para um período apenas - nos demais, a variável é livre para se mover em qualquer direção). A evidência empírica para o caso brasileiro sobre a resposta da taxa de câmbio aum choque contracionista de política monetária é ainda inconclusiva (há evidências de puzzles e do efeito usual da literatura teórica). Já as restrições de curto prazo seguem o padrão na literatura para economias fechadas, ou seja, a política monetária reage a todos os choques, porém as variáveis macroeconômicas reagem com uma defasagem aos choques de política monetária. Os resultados obtidos nos permitem afirmar que a política monetária no Brasil responde de forma significativa a choques na taxa de câmbio, no período analisado. Além disso, não encontramos evidências significativas de qualquer puzzle na resposta da taxa de câmbio e da inflação. Comparando os resultados com a identificação recursiva via decomposição de Cholesky, verifica-se que a resposta da política monetária a choques na taxa de câmbio é bem menos expressiva. Os principais resultados são robustos a uma série de especificações do modelo.

\section{Referências}

ADOLFSON, M. Monetary Policy with Incomplete Exchange Rate Pass Through. Working Paper Series, No.127, Sveriges Riksbank, 2001.

BARBOSA, F. H; SOARES, J. J. S. Regra de Taylor no Brasil: 1999-2005. In: ENCONTRO DA ANPEC, 2006.

BJØRNLAND, H. C. Monetary Policy and Exchange Rate Interactions in a Small Open Economy. Scandinavian Journal of Economics, v.110, n.1, p.197-221, 2008. 
BJØRNLAND, H. C. Monetary policy and exchange rate overshooting: Dornbusch was right after all. Journal of International Economics, v.79, p.64-77, 2009.

BJØRNLAND, H. C.; HALVORSEN, J. I. How does monetary policy respond to exchange rate movements? New international evidence. Oxford Bulletin of Economics and Statistics, v.76, n.2, p.208-232, 2014.

BONSER-NEAL, C.; ROLEY, V.; SELLON, G. Monetary Policy Actions, Intervention, and Exchange Rates: A Reexamination of the Empirical Relationships Using Federal Funds Rate Target Data. Journal of Business, v.71, p.147-177, 1998.

CARVALHO, F. A.; VALLI, M. Fiscal Policy in Brazil through the Lens of an Estimated DSGE model. Working Paper Series, Central Bank of Brazil, n. 240, 2011.

CHRISTIANO, L. J.; EICHENBAUM, M.; EVANS, C. L. Monetary Policy Shocks: What Have We Learned and to What End? In: TAYLOR, J. B.; WOODFORD, M. (Eds.). Handbook of Macroeconomics. v.1A, p. 65-148. Elsevier Science, 1999.

DORNBUSCH, R. Expectations and Exchange Rate Dynamics. Journal of Political Economy., v.84, p.1161-1176, 1976.

EICHENBAUM, M. Comments on "Interpreting the Macroeconomic TimeSeries Facts: The Effects of Monetary Policy": by Christopher Sims'. European Economic Review, v. 36, n.5, p.1001-1011, 1992.

EICHENBAUM, M.; EVANS, C. L. Some Empirical Evidence on the Effects of Shocks to Monetary Policy on Exchange Rates. The Quarterly Journal of Economics, p. 975-1009, 1995.

FAUST, J.; ROGERS, J. H. Monetary Policy's Role in Exchange RateBehavior', Journal of Monetary Economics, v. 50, n. 7, p 1403-1424, 2003.

FRY, R.; PAGAN, A. Sign Restrictions in Structural Vector Autoregressions: A Critical Review. Journal of Economic Literature, v. 49, n.4, 2011.

FURLANI, L. G. C.; PORTUGAL, M. S.;LAURINI, M. P. Exchange rate movements and monetary policy in Brazil: econometric and simulation evidence. Economic Modelling, v. 27, n. 1, 2010.

HOLLAND, M. Monetary and exchange rate policy in Brazil after inflation targeting. Berkeley: University of California, 2005.

IVENDRI, M; YILDIRIM, Z. Monetary Policy Shocks and Macroeconomic Variables: Evidence from Fast Growing Emerging Economies. Economics Discussion Paper, 2013.

KEARNS, J.; MANNERS, P. The Impact of Monetary Policy on the Exchange Rate: A Study Using Intraday Data. International Journal of Central Banking, v.2, p.157-183, 2006.

KIM, S.; ROUBINI, N. Exchange Rate Anomalies in the IndustrialCountries: A Solution With a Structural VAR Approach. Journal of Monetary Economics, v. 45, n. 3, p. 561-586, 2000.

KOHLSCHEEN, E. The Impact of Monetary Policy on the Exchange Rate: A High Frequency Exchange Rate Puzzle in Emerging Economies. Journal of International Money and Finance, v.44, C, p.69-96, 2013.

LIMA, E. C. R.; MAKA, A.; ALVES, P. Monetary Policy and Exchange Rate Shocks in Brazil: Sign Restrictions versus a New Hybrid Identification Approach. Brazilian Review of Econometrics, v. 31, n. 1, p. 97-136, 2011. 
LUBIK, T. A.; SCHORFHEIDE, F. Do central banks respond to exchange rate movements? A structural investigation. Journal of Monetary Economics, v.54, p.1069-1087, 2007.

MINELLA, A. et al. Inflation targeting in Brazil: construction credibility under exchange rate volatility. Trabalhos para Discussão, 77. Brasília: Banco Central do Brasil, 2003.

OLIVEIRA, N. S. M. et al. Testando mudanças estruturais na regra de Taylor: um estudo empírico para o Brasil (2000-2011). Revista de Economia, v. 39, n. 2 (ano 37), p. 28-50, 2013.

PALMA, A. A.; PORTUGAL, M. S. Preferences of the Central Bank of Brazil under the inflation targeting regime. Journal of Policy Modeling, v. 36, n.5, 2014.

SALGADO, M. J. S. et al. Monetary policy during Brazil's Real Plan: estimating the central bank's reaction function. Revista Brasileira de Economia, v. 59, n.1, 2005.

SIMS, C.; UHLIG, H. Understanding unit rooters: A helicopter tour. Econometrica, v. 59, n.6, p. 1591-1599, 1991.

SVENSSON, L. Open-economy inflation targeting. Journal of International Economics, v. 50, p. $155-183,2000$.

TAYLOR, J. B. The role of the exchange rate in monetary policy rules. American Economic Review, v.91, p. 263-267, 2001.

UHLIG, H. What are the Effects of Monetary Policy on Output? Results from an Agnostic Identification Procedure. Journal of Monetary Economics, v. 52, p. 381-419, 2005.

ZETTELMEYER, J. The impact of monetary policy on the exchange rate: evidence from three small open economies. Journal of Monetary Economics, v. 51, p. 635-652, 2004.

\section{Sobre a autora}

Andreza Aparecida Palma - drepalma@ufscar.br

Universidade Federal de São Carlos, Departamento de Economia, Sorocaba, São Paulo.

\section{Sobre 0 artigo}

Recebido em 19 de julho de 2015. Aprovado em 07 de março de 2016. 


\section{Apêndice A}

Análise de Robustez

Figura A1 Modelo estimado sem tendência e com o hiato do produto

\section{Impulso Resposta}

Choque PM
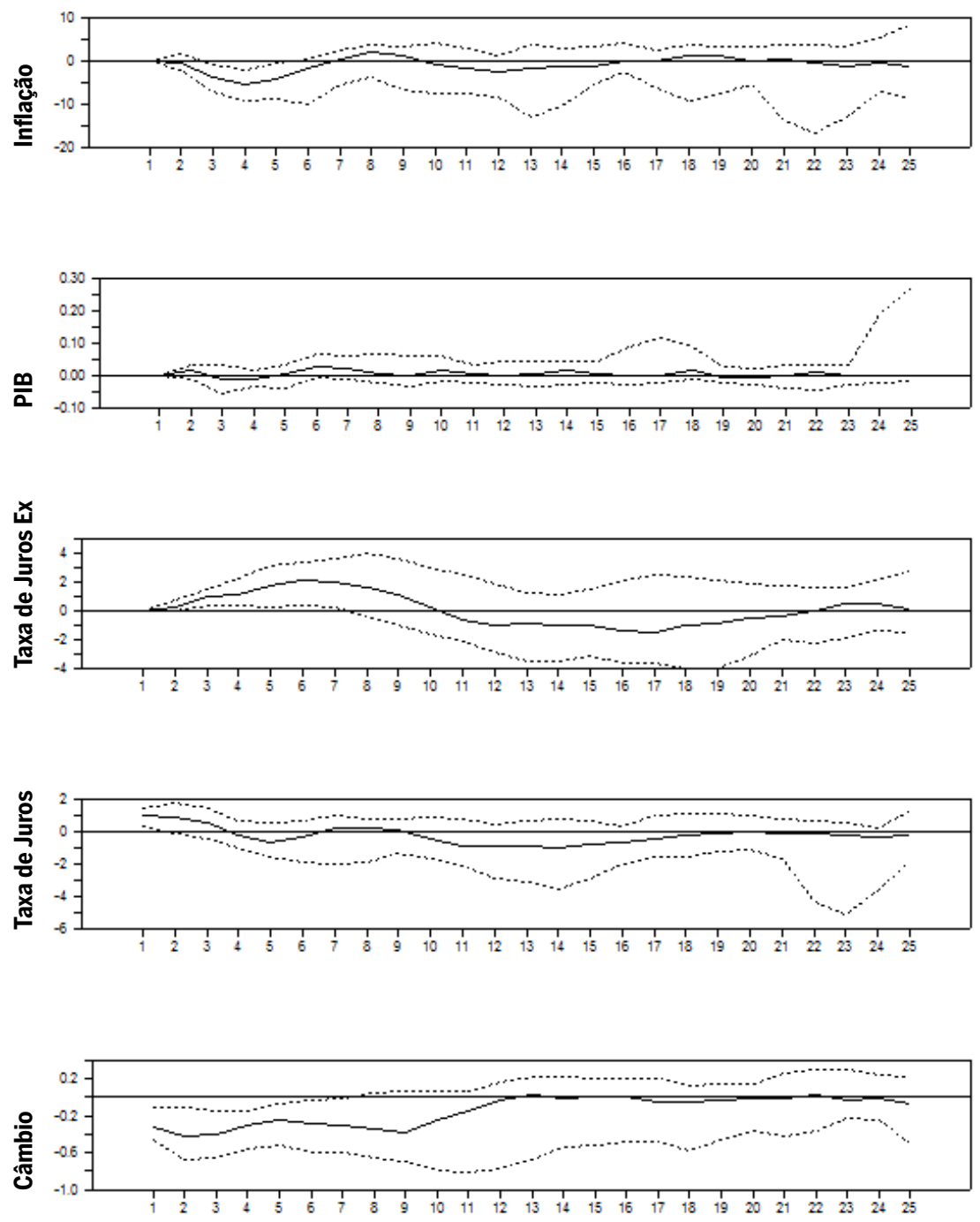


\section{Impulso Resposta}

\section{Choque Câmbio}
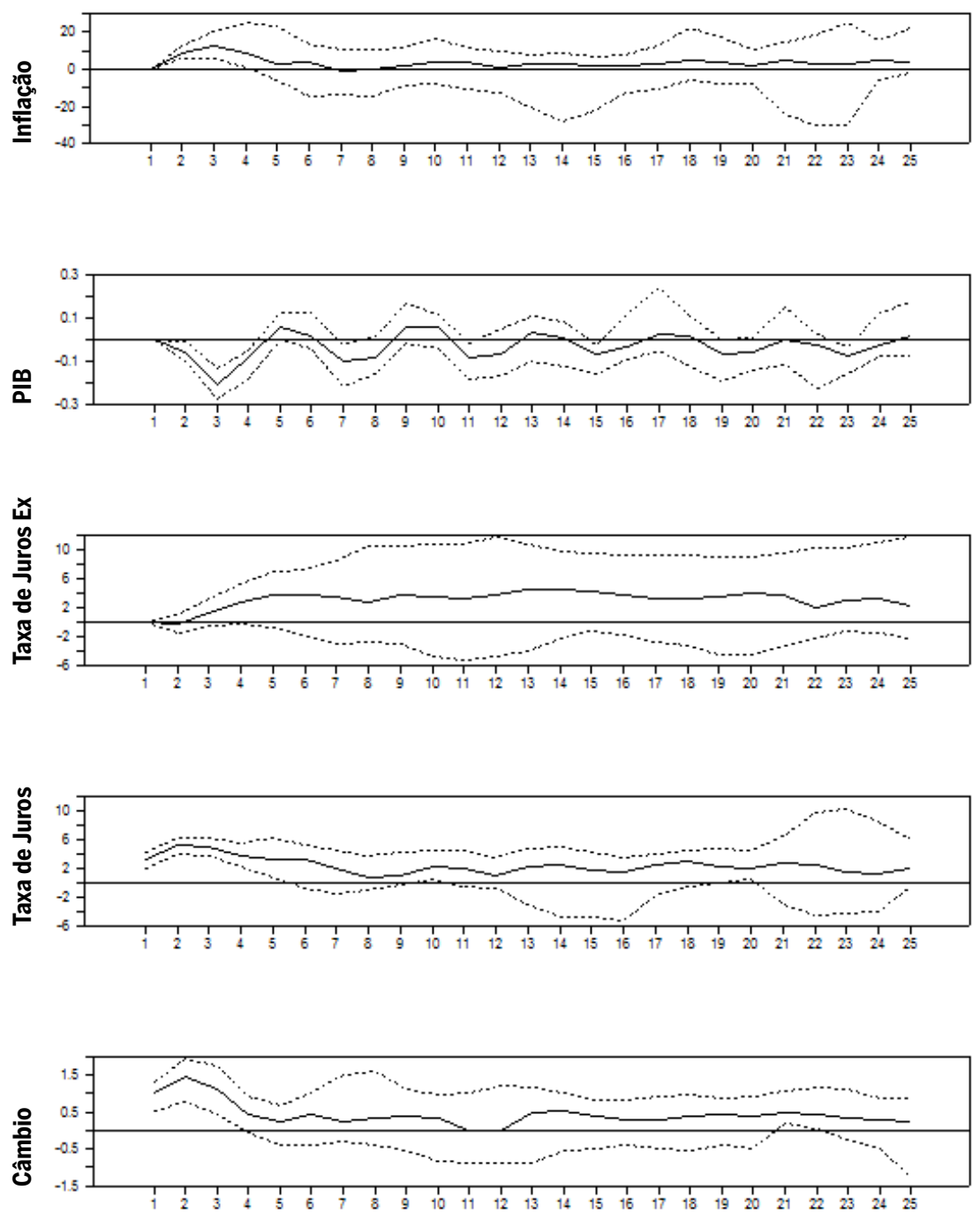
Figura A2 Modelo estimado com duas defasagens

\section{Impulso Resposta}

Choque PM
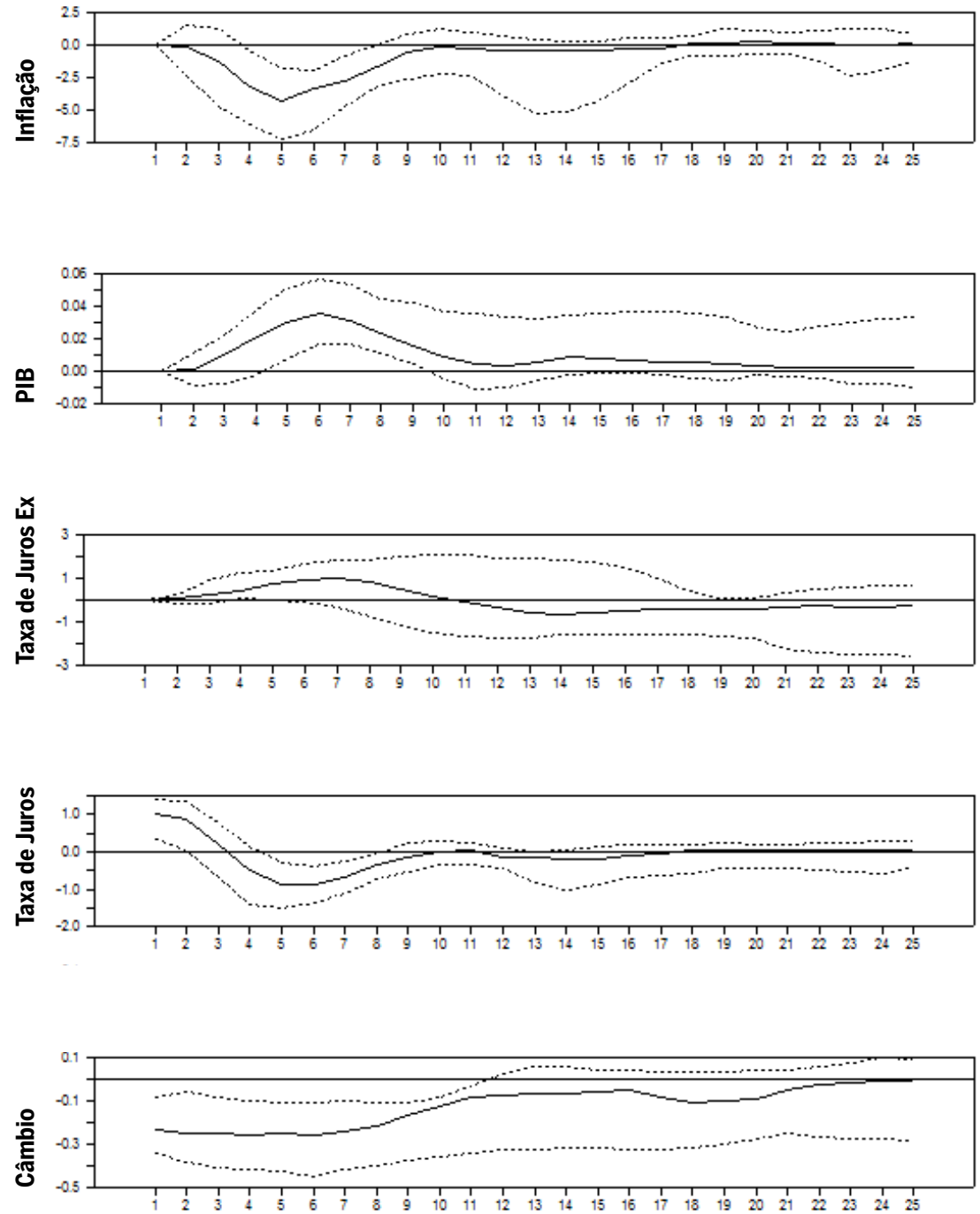


\section{Impulso Resposta}

Choque Câmbio
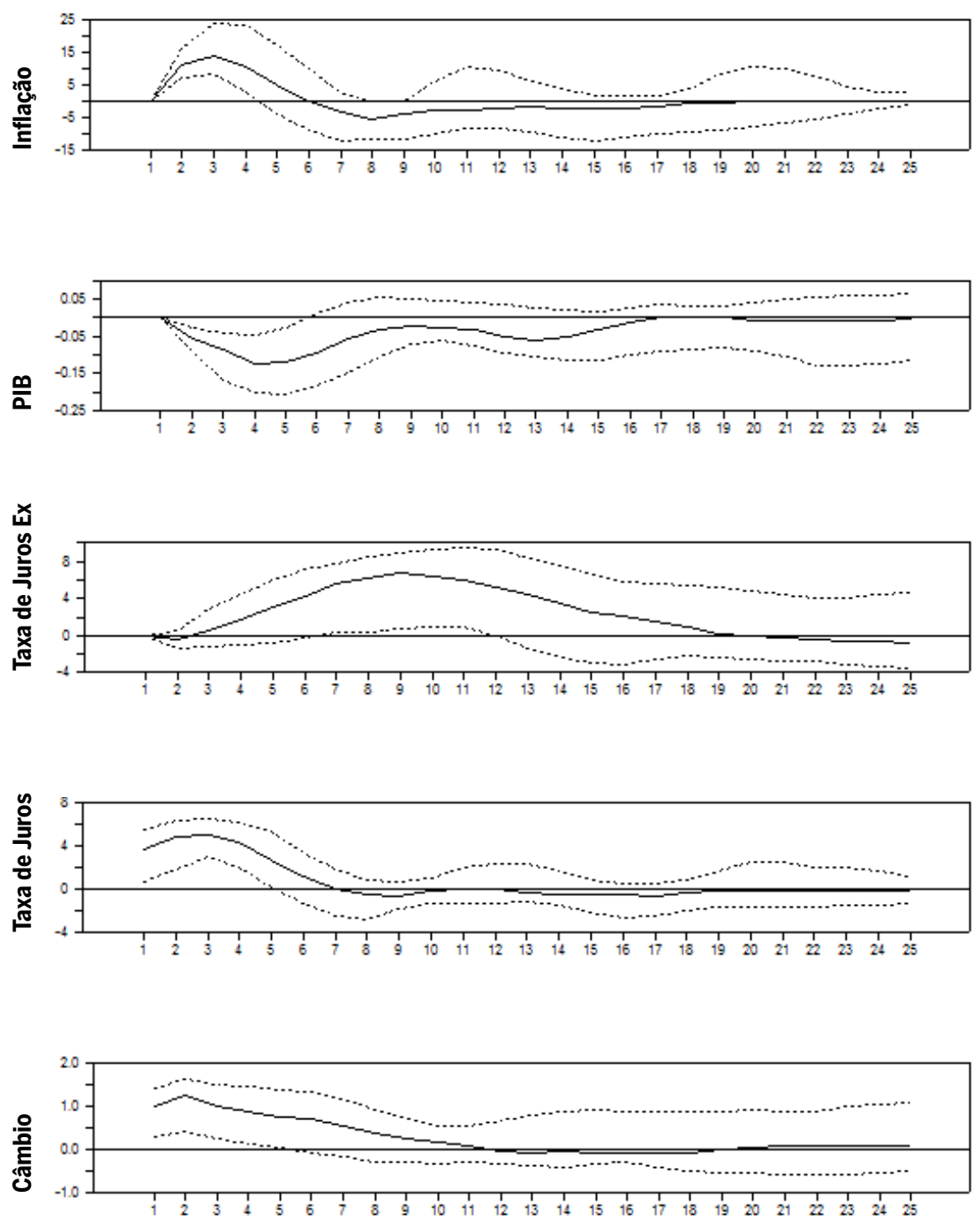
Figura A3 Modelo estimado com índice de preços de commoditties como variável exógena

Impulso Resposta

Choque PM
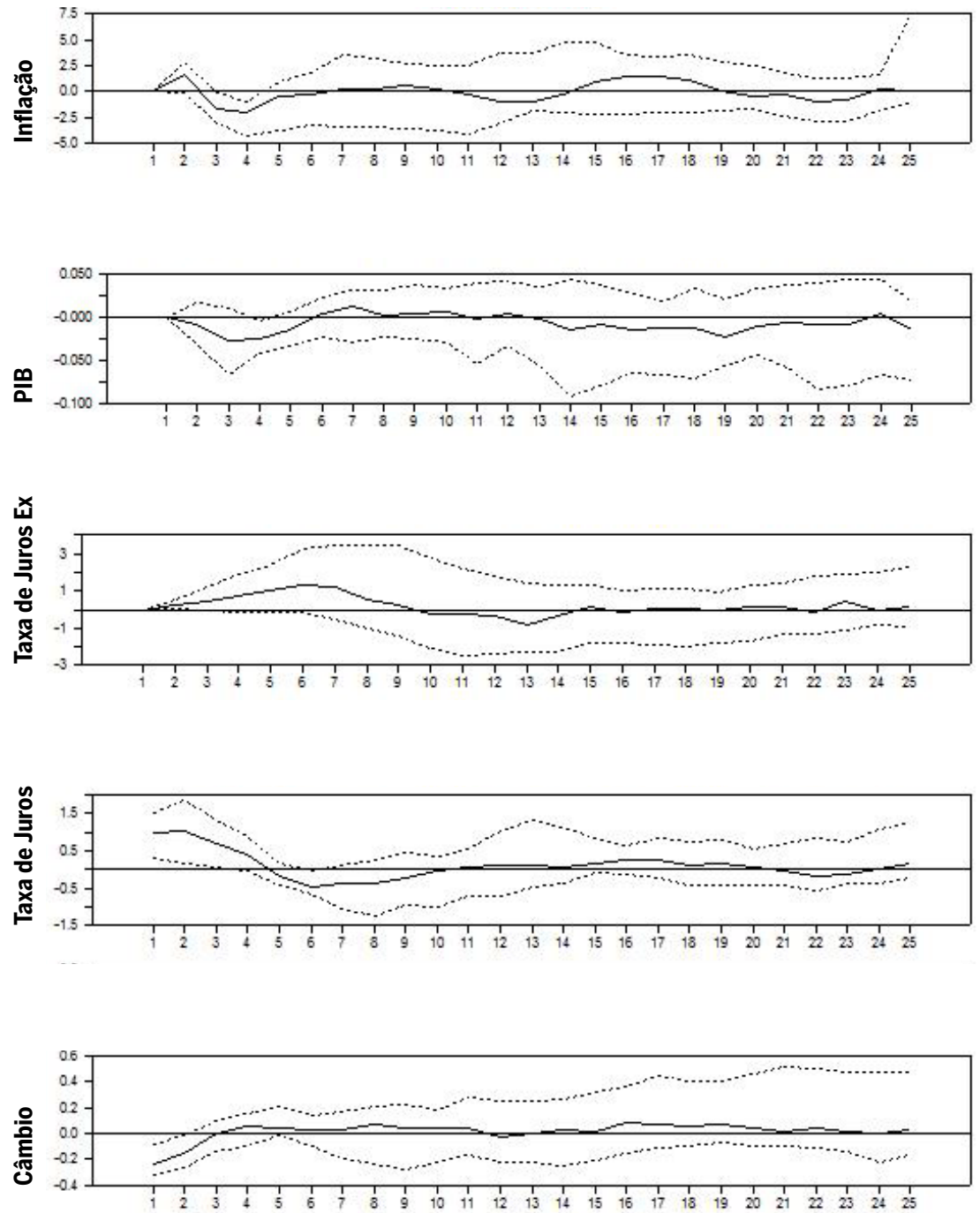


\section{Impulso Resposta}

Choque Câmbio
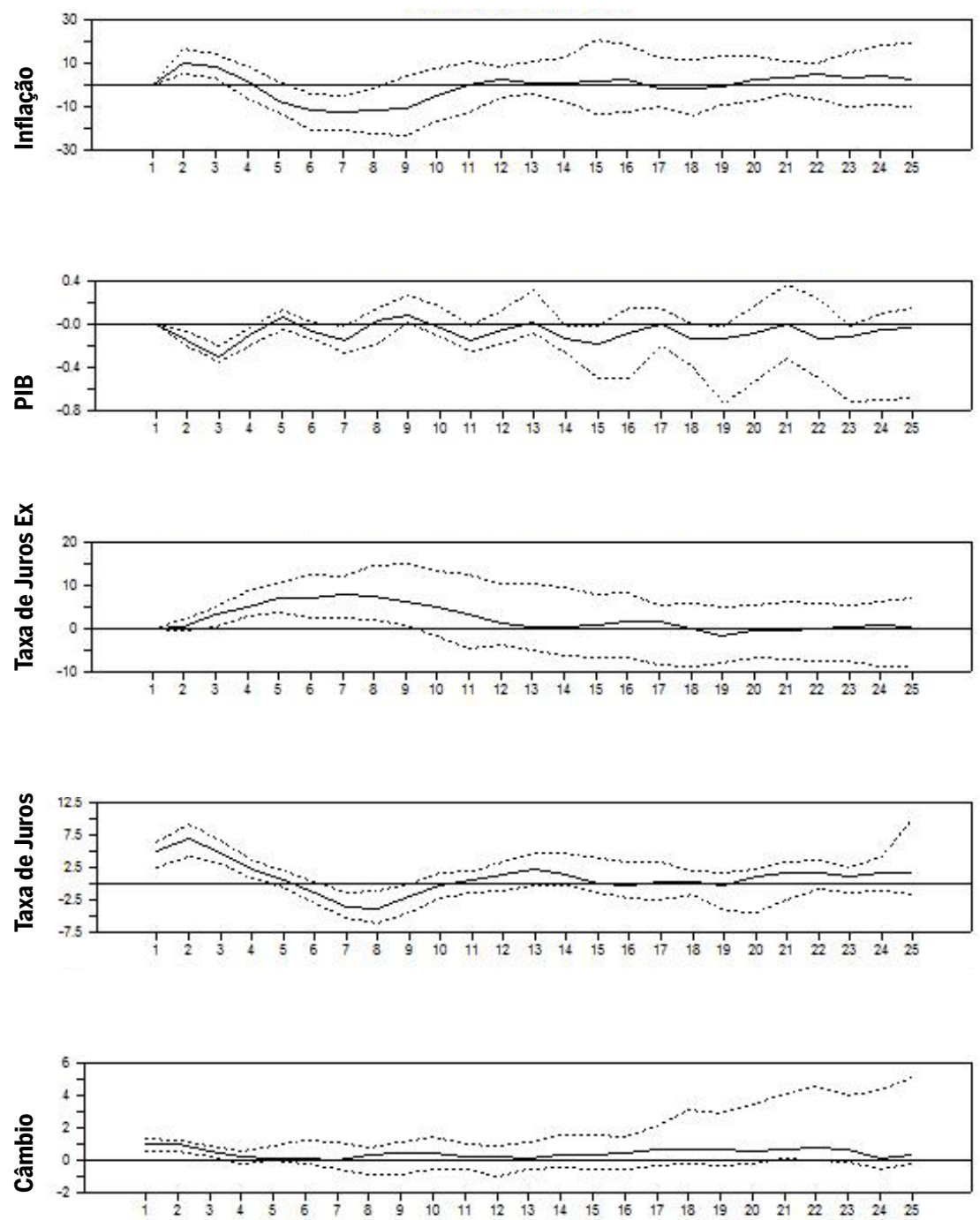
Figura A4 Modelo estimado com a taxa de câmbio real efetiva

\section{Impulso Resposta}

Choque PM
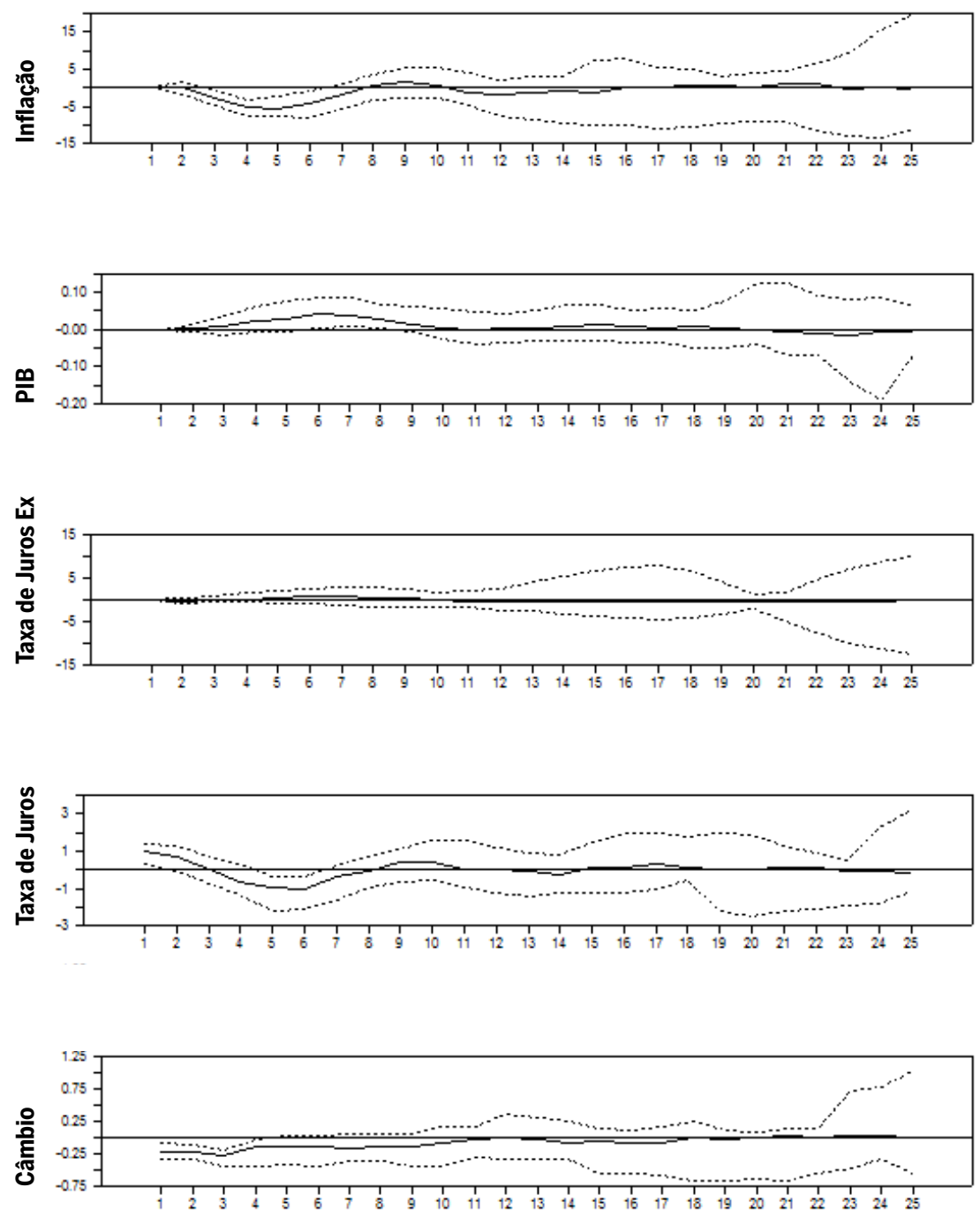


\section{Impulso Resposta}

Choque Câmbio
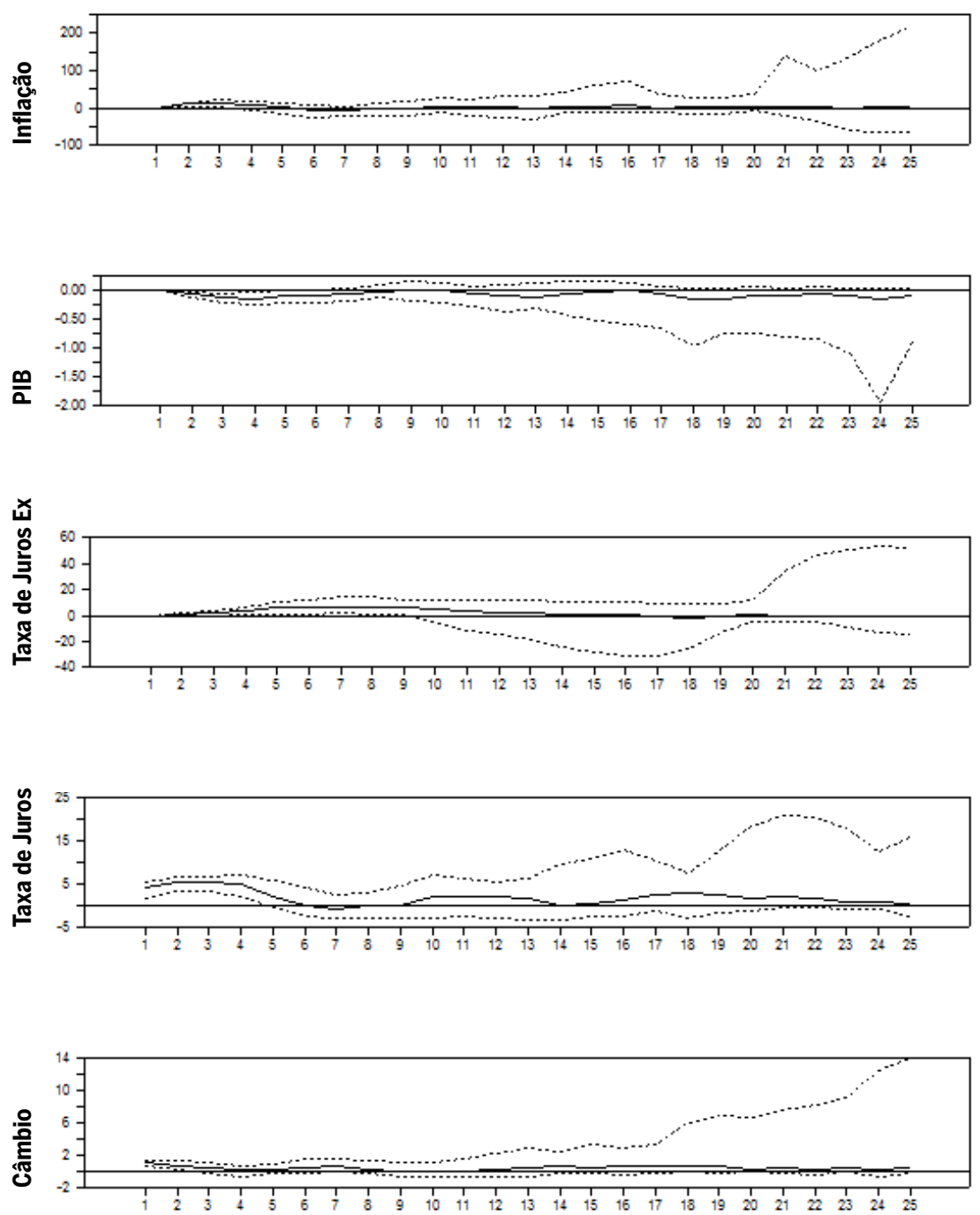
Figura A5 Modelo estimado com a variação da taxa de câmbio

\section{Impulso Resposta}

Choque PM
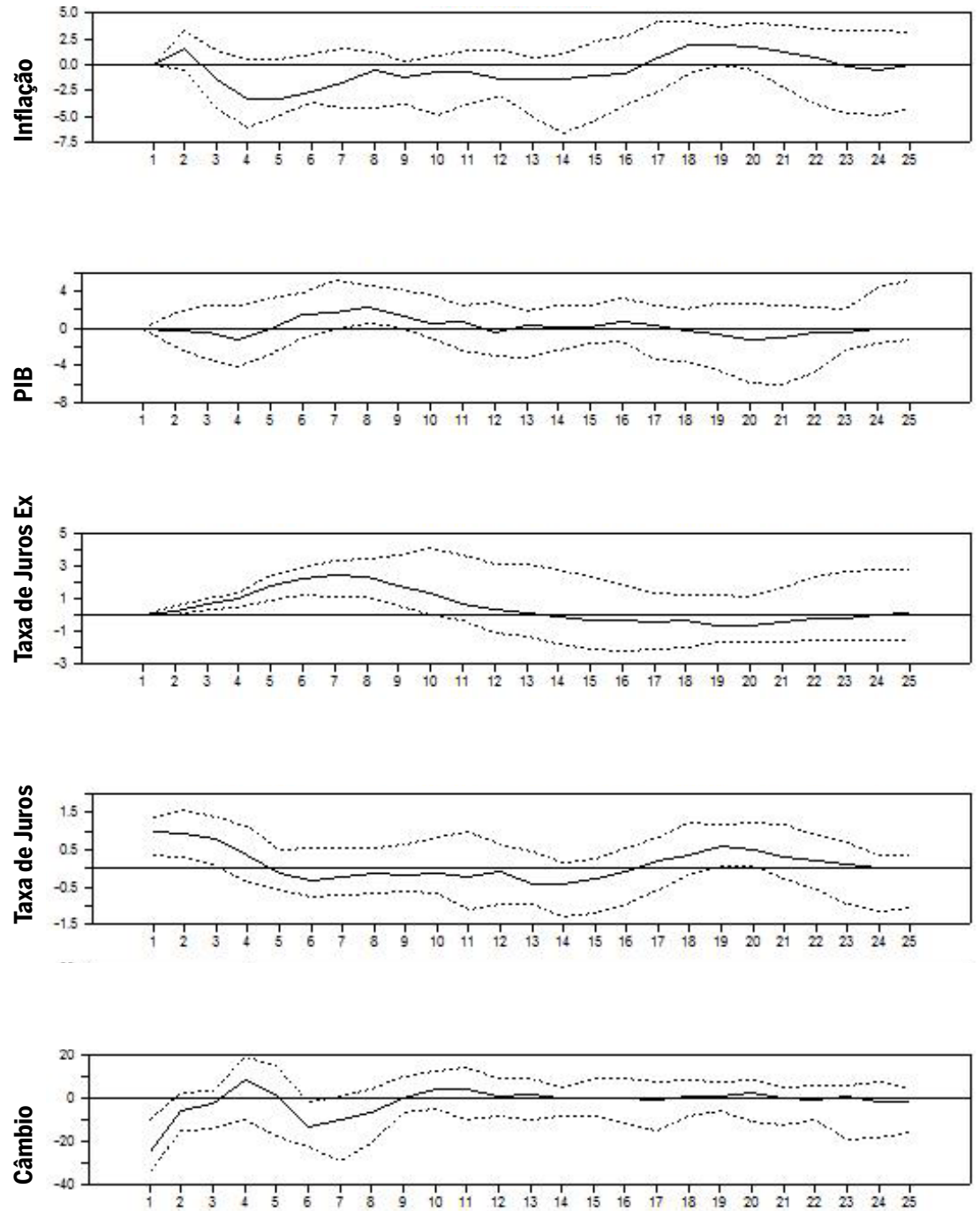


\section{Impulso Resposta}

\section{Choque Câmbio}
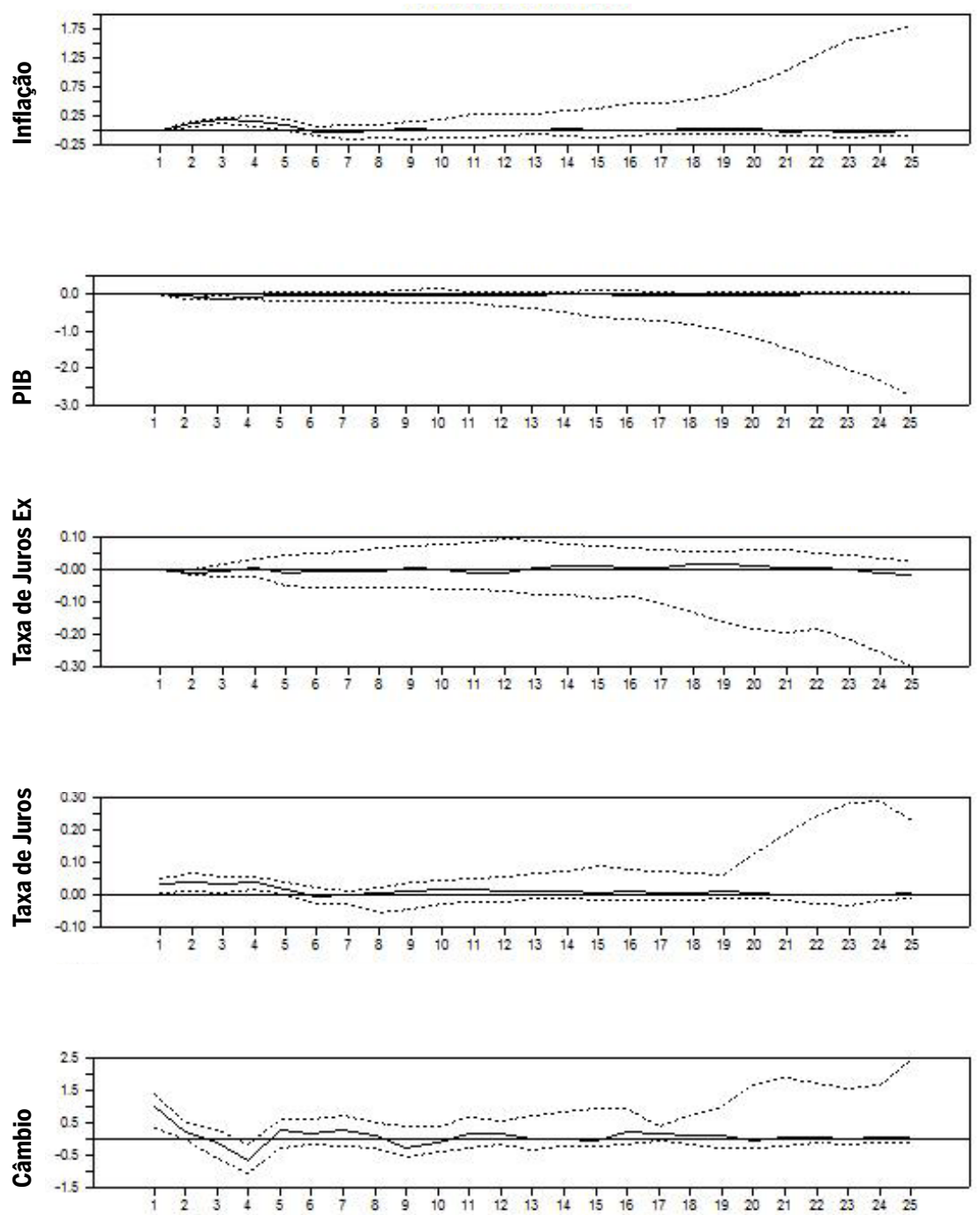
Figura A6 Modelo estimado com dummy "Efeito Lula" e dois lags

\section{Impulso Resposta}

Choque PM
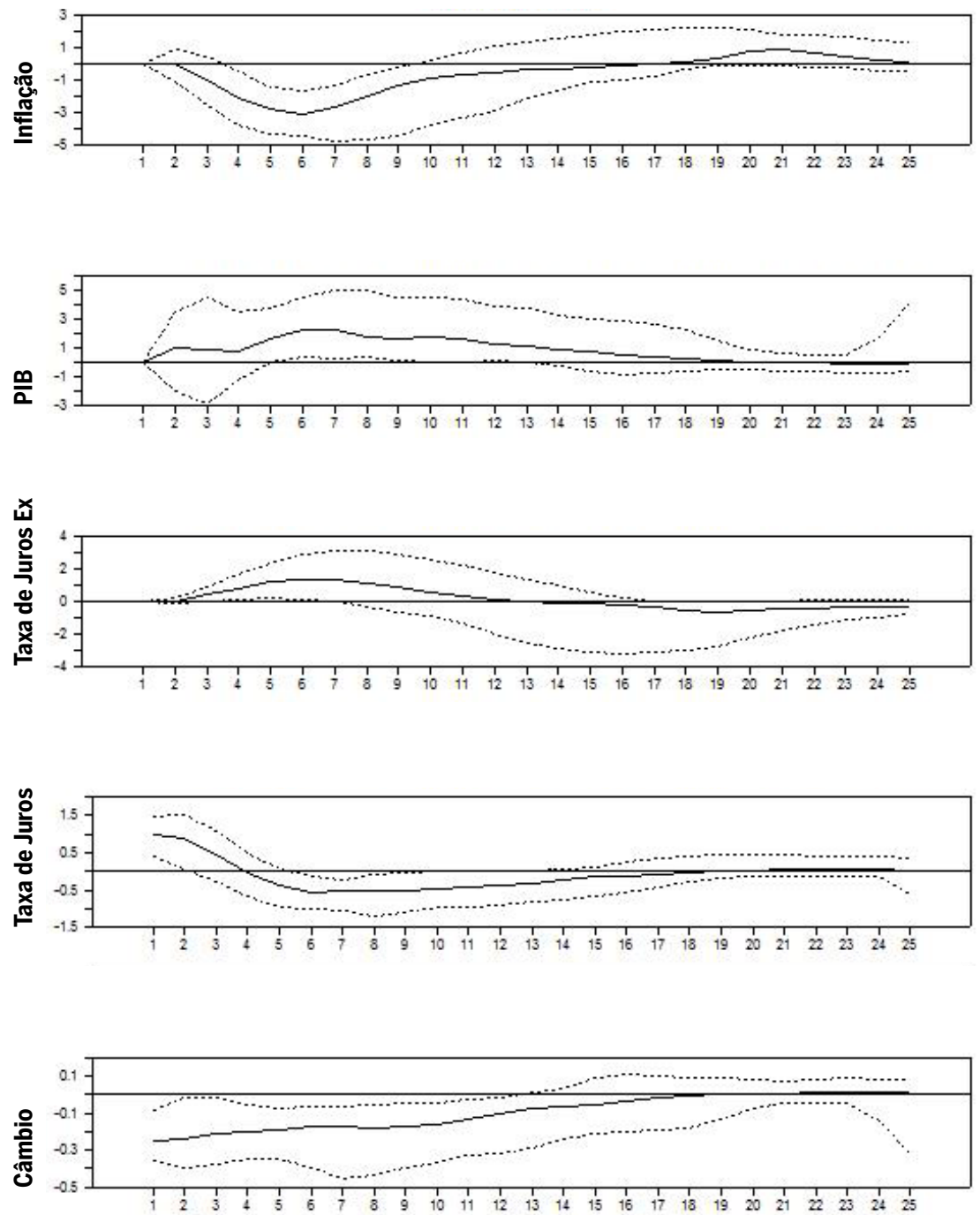


\section{Impulso Resposta}

\section{Choque Câmbio}
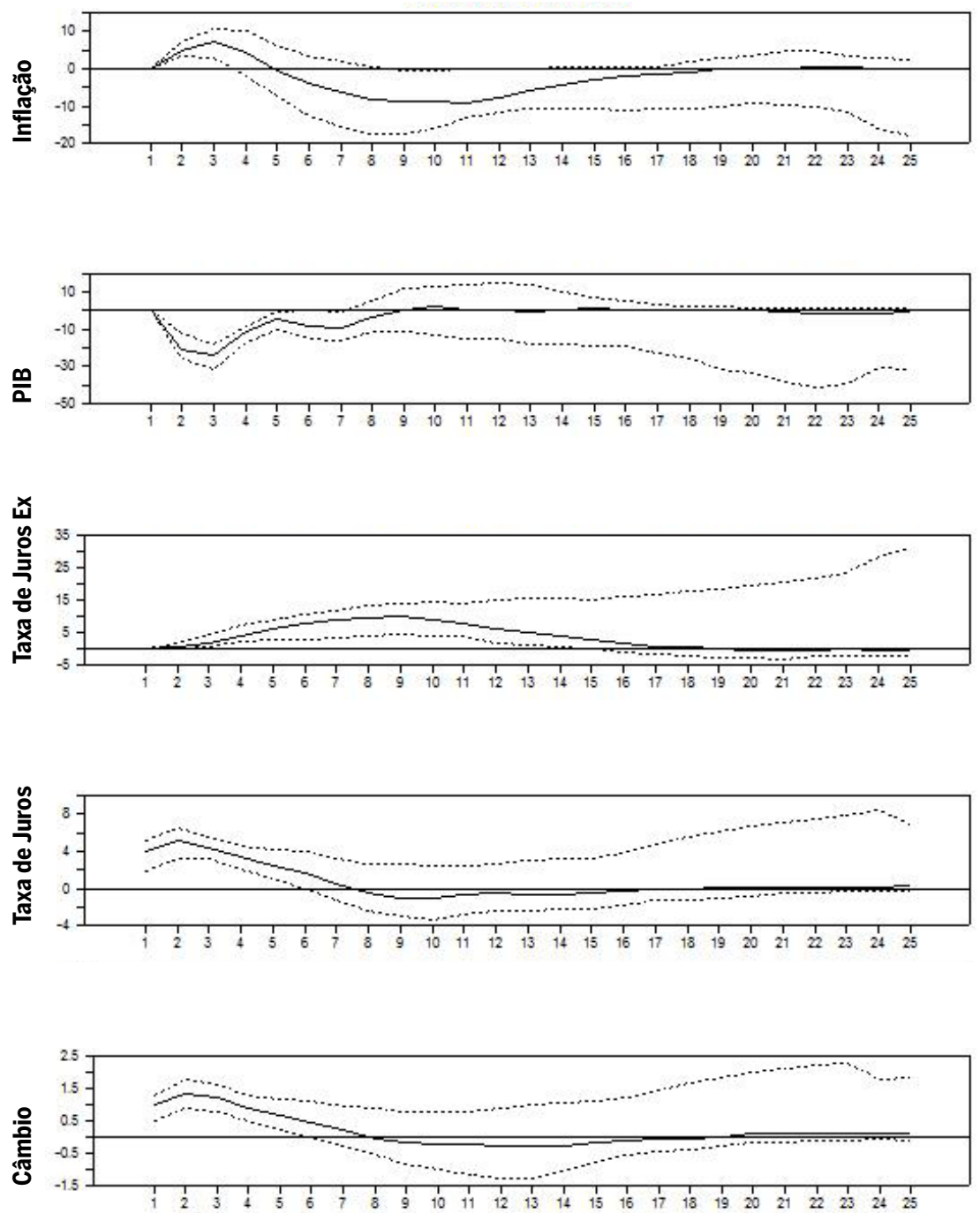
Figura A7 Modelo estimado com dummy “crise 2008" e 2lags

Impulso Resposta

Choque PM
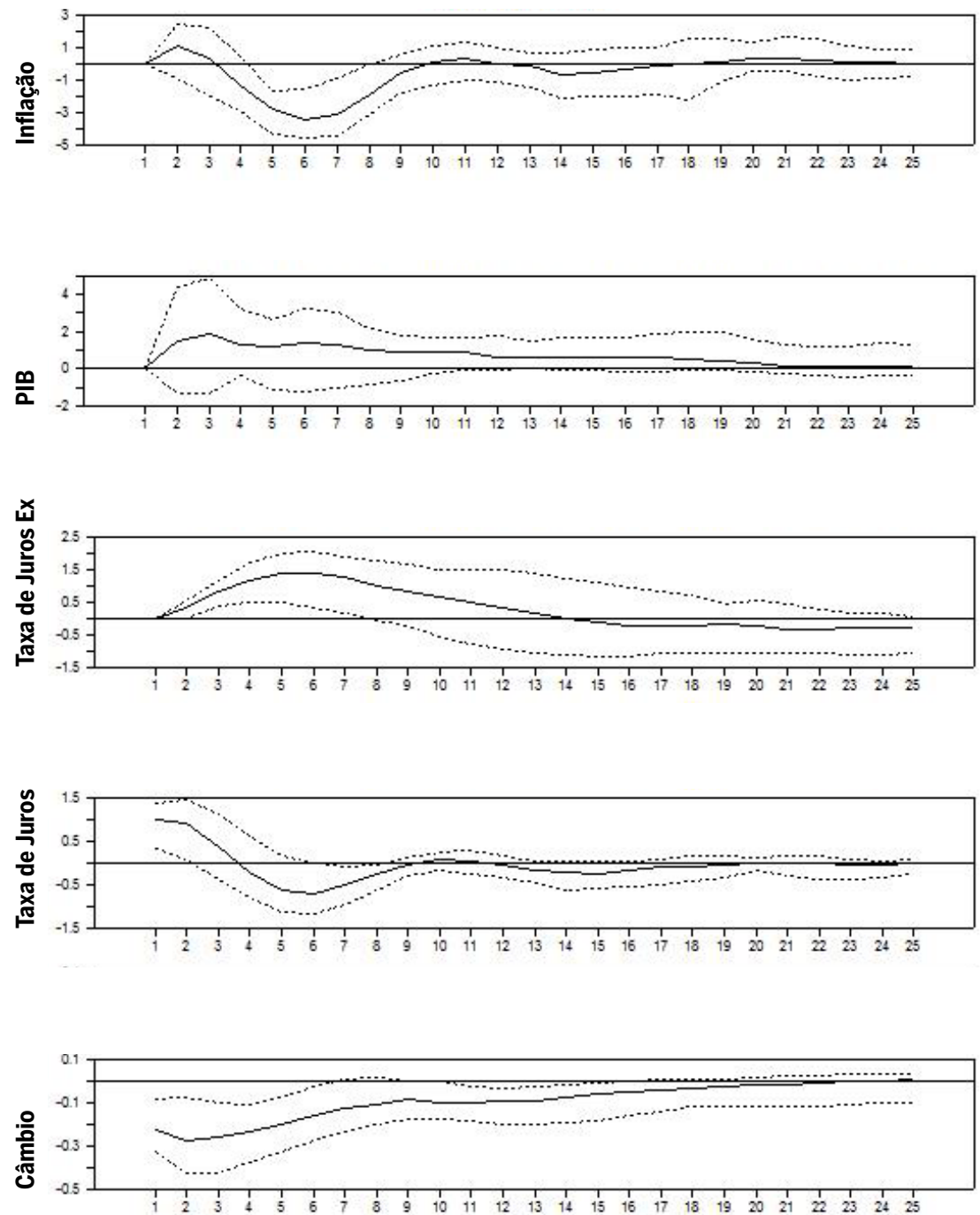


\section{Impulso Resposta}

\section{Choque Câmbio}
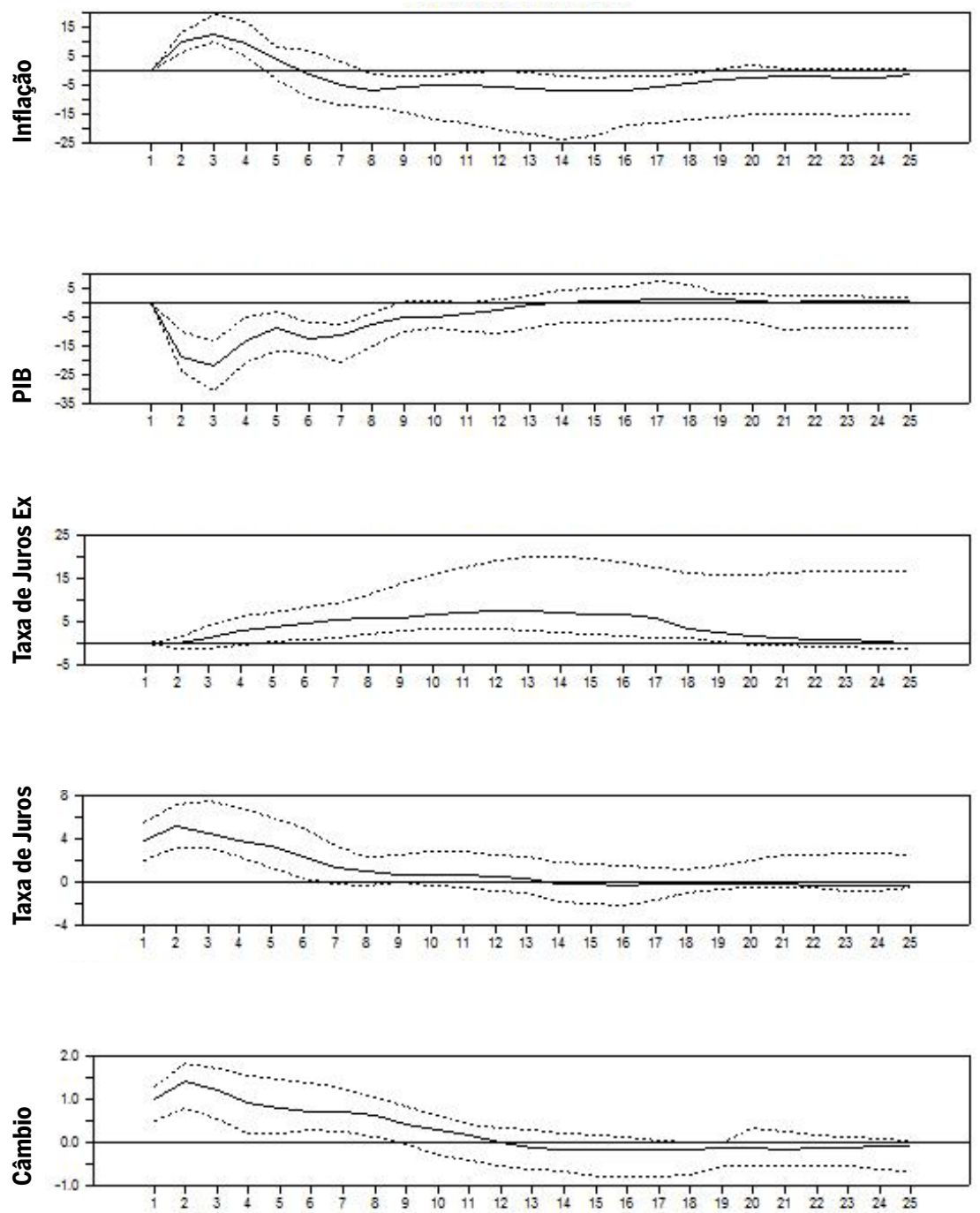
Figura A8 Modelo estimado com dummy “Tombini” e 2lags

\section{Impulso Resposta}

Choque PM
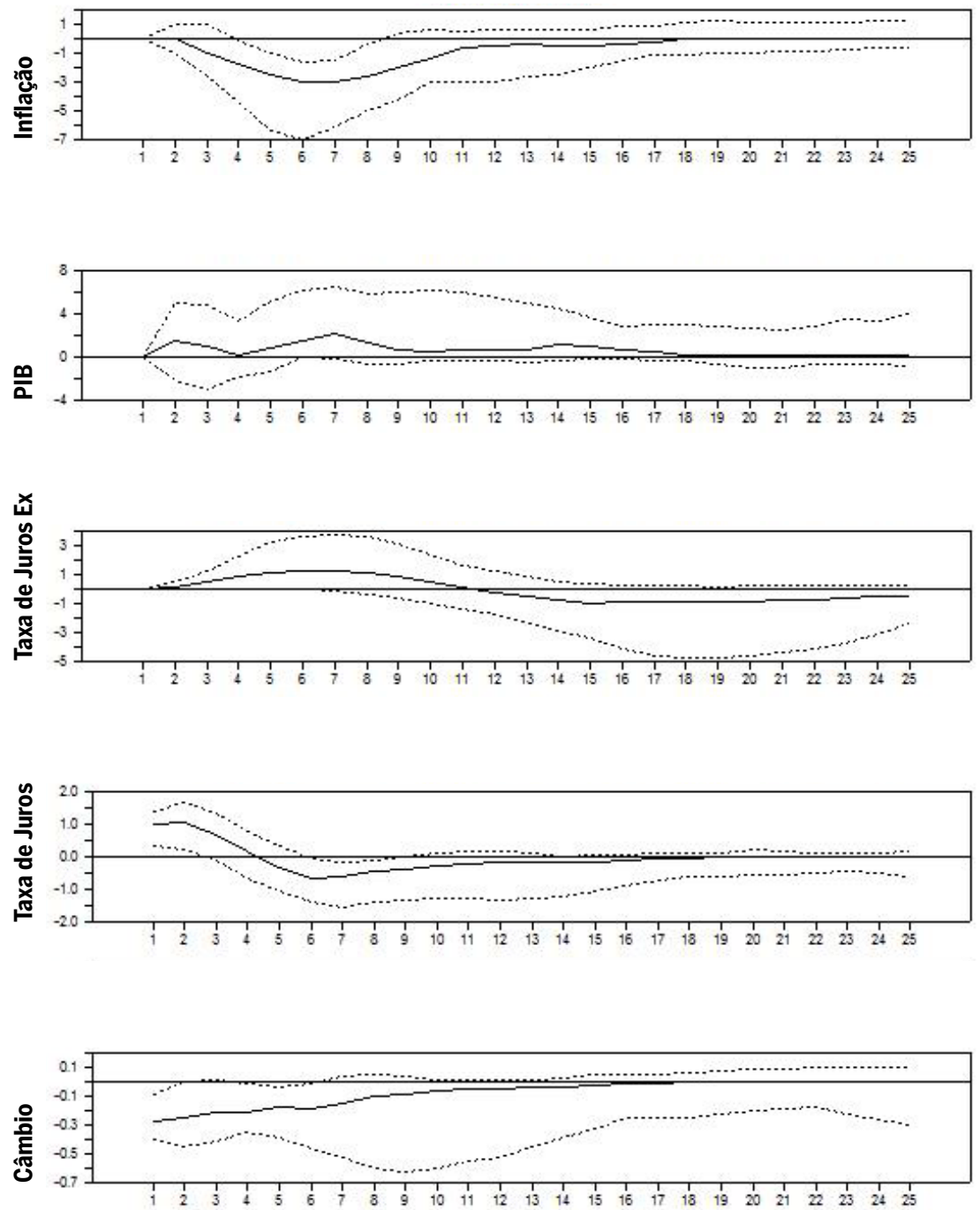


\section{Impulso Resposta}

Choque Câmbio
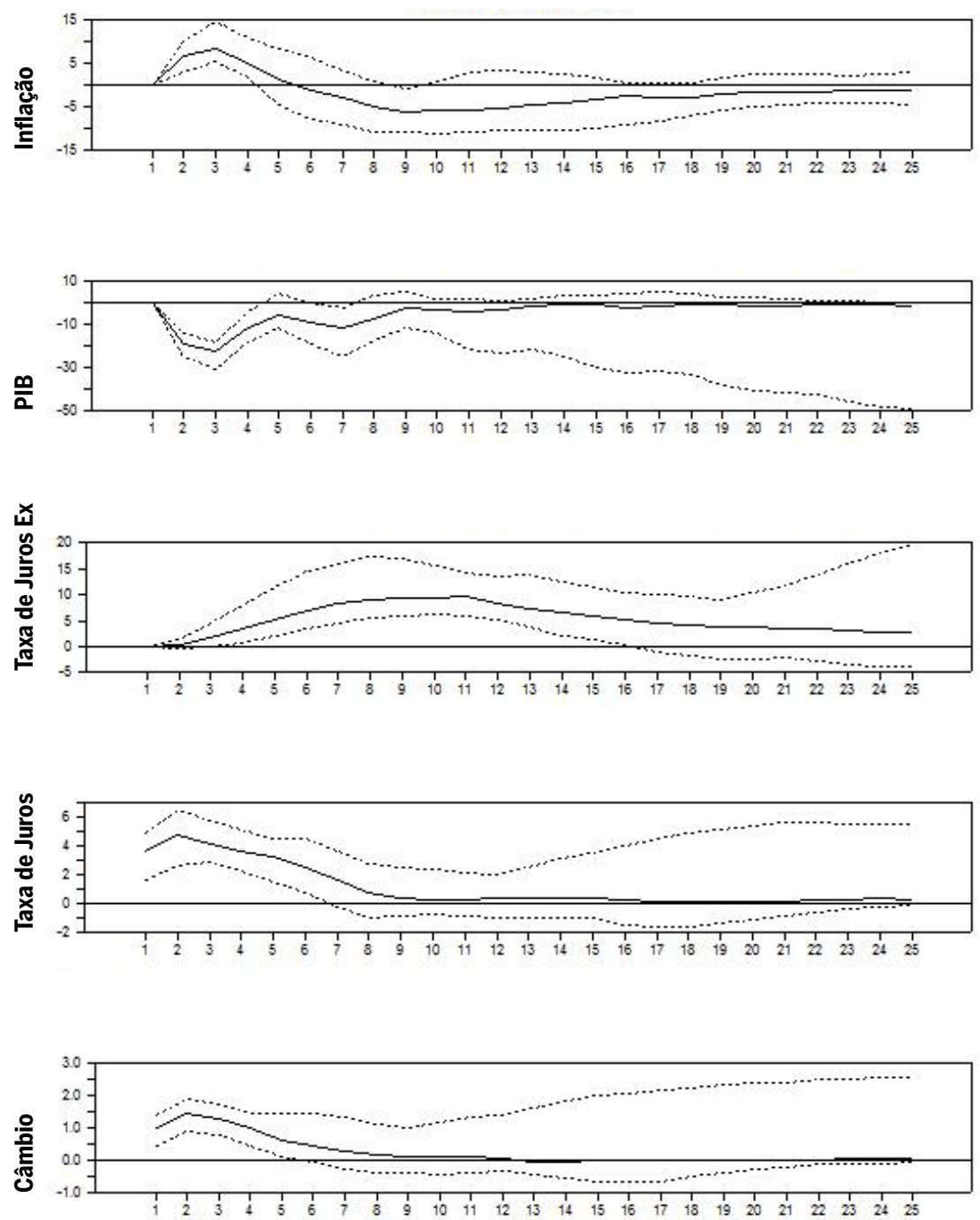


\section{Apêndice $B$}

Diagnóstico: resíduos (VAR na forma reduzida)
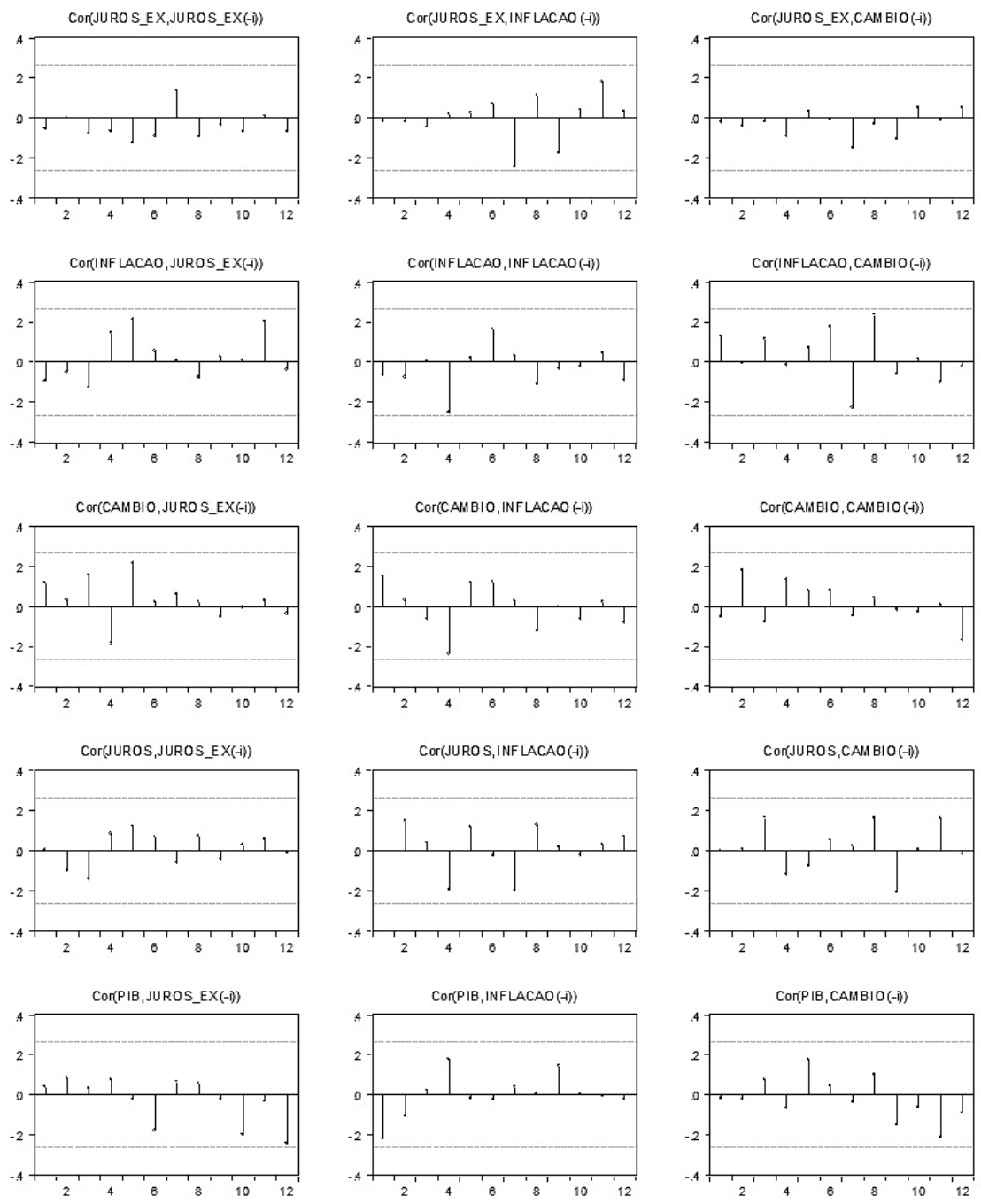

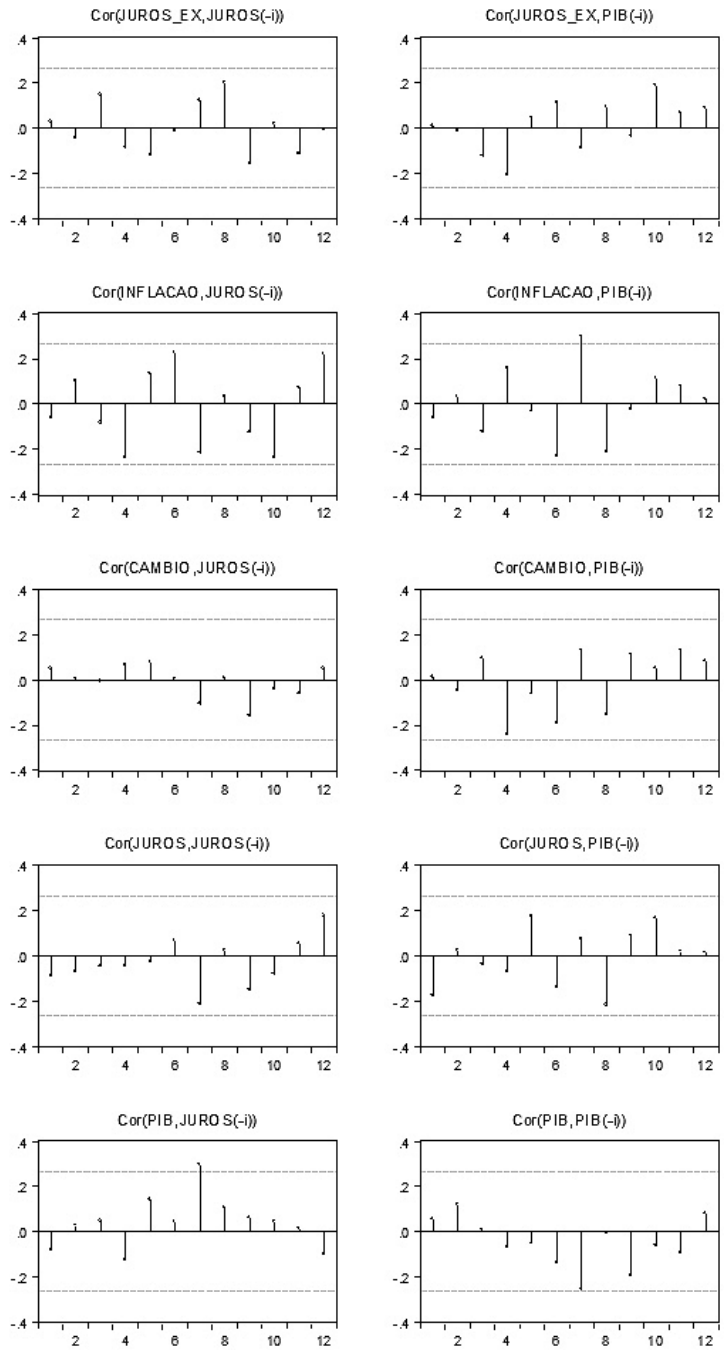